$$
y_{0}^{2 m}
$$


Distribuclón del ingreso e incidencia de la pobreza a lo largo del ajuste

Oscar Altimir

Nuevas orientaciones para la gestión pública

Eugenio Lahera

Industrias petroquímica y de máquinas herramientas:

estrategias empresariales

Daniel Chudnovsky, Andrés López y Fernando Porta

Productividad, crecimiento y exportaciones industriales de Brasil

Regis Bonelli

Maquila en el Caribe: la experiencia de Jamaica

Larry Willmore

Elasticidad-precio de las exportaciones agrícolas de Centroamérica

De la inflaclón crónica a la inflación moderada en el Ecuador

Luis I. Jácome Hidalgo

Nuevas estrategias de las empresas transnacionales en la Argentina

Bernardo Kosacoff y Gabriel Bezchinsky

Informalidad y pobreza en América Latina

Guillermo Rosenbluth

Crisis y alternativas en los procesos de regionalización

Sergio Boisier

Una perspectiva cultural de las propuestas de la CEPAL

Fernando Calderón, Martín Hopenhayn y Ernesto Ottone

La CEPAL y el neoliberalismo: entrevista a Fernando Fajnzylber

Orientaciones para los colaboradores de la Revista de la CEPAL

Publicaciones reclentes de la CEPAL 


\section{Nuevas estrategias de las empresas transnacionales en la Argentina}

\section{Bernardo Kosacoff Gabrlel Bezchinsky}

Experto y Coordinador de los estudios sobre desarrollo industrial de la Oficina de la CEPAL en Buenos Aires.

Consultor de la misma Oficina.
En este artículo se analizan las tendencias actuales de la participación de las empresas transnacionales en la industria argentina, considerando los cambios estructurales que se están produciendo en los escenarios doméstico, regional e internacional, y comparándolos con las condiciones imperantes durante la vigencia del modelo de sustitución de importaciones. En la primera sección se caracteriza el nuevo contexto nacional e internacional, en el que todas las empresas se ven forzadas a redefinir sus estrategias de producción, comerciales, financieras y tecnológicas. En este sentido, las subsidiarias de las empresas transnacionales en la Argentina son los actores principales de este proceso. En la segunda sección se evalúan los rasgos básicos de la presencia de las transnacionales en la industria argentina, y se señalan las diferencias entre las condiciones actuales y las imperantes en el período de sustitucion de importaciones. A partir de la información recabada de las principales empresas transnacionales en 1992, en la sección tercera se presentan algunos de los rasgos más destacados de la transición en las estrategias de dichas empresas en relación con la transformación económica de la Argentina y su inserción internacional. En la sección cuarta se hacen algunos comentarios finales. 


\section{I}

\section{Introducción}

La economía argentina ha sufrido una serie de cambios estructurales importantes en las últimas dos décadas. Estos cambios, que afectan las estructuras productivas en su raíz, han sido particularmente intensos en el sector industrial. Si bien el nuevo modelo de industrialización aún no se ha terminado de definir, es evidente que en la etapa actual difiere sustancialmente del modelo basado en la sustitución de importaciones, que rigió en el país desde principios de la década de 1930 hasta fines de los años setenta (Katz y Kosacoff, 1989; Kosacoff, 1992).

Estas modificaciones se manifiestan claramente en tres planos. En primer lugar, la economía actual es mucho más abierta comercial y financieramente que la del modelo anterior. En segundo lugar, el proceso de integración regional del Mercosur (iniciado en 1986) trae aparejadas importantes posibilidades por la extraordinaria ampliación del mercado que significa, pero al mismo tiempo enormes desafíos, debido a la intensificación de la competencia. Más allá de estas señales, y de las dificultades que existen para armonizar las políticas y eliminar las asimetrías entre los países miembros, el proceso es considerado por todos los actores económicos (y en especial por las empresas privadas) como una tendencia irreversible. En tercer lugar, nos encontramos ante un cambio significativo del contexto macroeconómico, que incluye un esfuerzo sistemático de estabilización y una profunda reforma del Estado, cuyos aspectos más salientes son el proceso de privatización de empresas públicas y los cambios en la regulación de las actividades económicas, que están transformando profundamente el funcionamiento del sistema económico.
También en el plano externo la economía está experimentando una serie de cambios fundamentales. Las nuevas condiciones del escenario internacional se caracterizan por la intensificación de la competencia, que se evidencia en la creciente globalización de la economía, viabilizada por la reciente dinámica de las inversiones extranjeras directas (IED) que realizan las empresas transnacionales (ETs), determinada por sus ventajas de propiedad, internalización y localización, con una alta concentración en la Tríada (Estados Unidos, la Comunidad Europea y Japón) (Mortimore, 1992a; Dunning, 1988; CET, 1991).

Esta nueva forma de globalización se relaciona con los profundos cambios tecnológicos y de organización industrial y con la nueva especialización del comercio caracterizada por la dinámica participación de bienes cuya producción requiere el uso intensivo del conocimiento (Ostry, 1992; OCDE, 1991; Lall, 1992; Gurrieri, 1991).

Los efectos estructurales de este dinamismo de las ETs son decisivos en las distintas etapas del desarrollo competitivo y dan pie a un debate en torno a los efectos de derrame de estas empresas, que actuarían como motor de crecimiento económico, y a las posibilidades de formular estrategias competitivas en los países semiindustrializados. Estas nuevas formas competitivas incluyen nuevas formas de inversión, entre las cuales destacan las alianzas estratégicas entre las ETs, que se han intensificado incentivadas por los desafíos de la innovación tecnológica y los cambios en la orientación del mercado como efecto de los acuerdos de integración regional (Ozawa, 1992; CET, 1992; Esser, 1992; Oman, 1984; Mytelka, 1990; Vernon, 1992).

\section{II}

\section{Rasgos básicos de la presencia de las empresas transnacionales en la industria argentina}

\section{El proceso de sustitución de importaciones}

Desde que se inició el proceso de industrialización en la Argentina y el país se integró activamente en la división internacional del trabajo, las empresas transnacionales han desempeñado un papel importante. En 
sus comienzos se especializaron en las actividades industriales que eran necesarias para viabilizar la exportación de materias primas, y posteriormente se hicieron presentes en todo el tejido industrial. En particular, a partir de fines de la década de $1950 \mathrm{y}$ durante los años sesenta, las ETs fueron el actor central en el período de profundización del proceso de sustitutición de importaciones, liderado por los sectores metalmecánico y petroquímico. Esta etapa se caracterizó por el excelente desempeño del sector industrial, que fue el motor del crecimiento económico hasta mediados de los años setenta.

La entrada masiva de ETs y su radicación en sectores dinámicos se tradujo en un fuerte incremento de su participación en el producto industrial, la que desde menos de una quinta parte en 1955 se llevó a cerca de un tercio a comienzos de la década de 1970. La modalidad de funcionamiento económico de estas empresas correspondía al modelo típico de una economía pequeña y protegida, cuyas inversiones se orientan casi en forma exclusiva a la explotación integral del mercado doméstico. Antes de que se establecieran en el país, el mercado se caracterizaba por la existencia de una importante demanda excedente, producto tanto de las dificultades con que se tropezaba para el abastecimiento vía importaciones (debido a las restricciones externas que caracterizaban a la economía argentina), cuanto a las limitaciones locales que existian para avanzar en los encadenamientos más complejos de la estructura industrial, en los cuales no bastaba la simple expansión mediante la incorporación de mano de obra adicional, sino que se requerían procesos tecnológicos y estructuras empresariales que no estaban lo suficientemente desarrollados en el medio local.

En estas condiciones, la ocupación de los "casilleros vacíos" de la producción industrial por el capital extranjero tuvo las siguientes características. En primer lugar, las ETs en comparación con las firmas competidoras de capital nacional operaban con plantas de mayor tamaño, la productividad de su mano de obra y sus salarios eran más elevados, como asimismo su coeficiente de importación y su dotación de capital por hombre empleado. En segundo lugar, su comportamiento tecnológico se basaba en la incorporación de equipamiento y prácticas de producción ya desarrollados en sus casas matrices que, a pesar de no ser los más avanzados internacionalmente, sin duda resultaron novedosos en el mercado local. Así, en muchos casos, como consecuencia de la radicación en el país de este tipo de empresas surgieron gradualmente planteles locales de ingeniería y de organización y métodos de trabajo destinados a adaptar productos y procesos a las condiciones de producción locales. En tercer lugar, estas empresas se financiaron básicamente a través del ahorro nacional por tener acceso preferencial a las líneas crediticias con tasa de interés negativa. Su aporte neto de divisas en el mediano plazo terminó siendo negativo, debido a que las transferencias al exterior eran mayores que los ingresos de capital efectuados.

Esta particular presencia de las ETs presentaba dos facetas muy distintas. Vistas desde la óptica del mercado local, estas empresas estaban entre las más importantes de la estructura industrial, con una ubicación preferencial en los mercados más dinámicos. Asimismo, se destacaban por haber generado una verdadera "revolución industrial", mediante un desempeño tecnológico y una organización del tejido industrial desconocidos en el país. Sin embargo, si el punto de referencia es el escenario internacional, estas subsidiarias resultaban ser marginales dentro de su propia estructura corporativa (muy raramente su participación en las ventas globales superaba el $1 \%$ ), y su desempeño tecnológico estaba muy alejado de las mejores prácticas internacionales.

La típica planta industrial de una subsidiaria local de las ETs no superaba, por lo general, la décima parte de una planta que producía un bien similar en los países desarrollados. A su vez, la fragilidad del tejido industrial local se caracterizaba por la escasez de proveedores especializados y subcontratistas. Estos dos factores determinaban la pérdida de economías de escala y de especialización. La introducción al medio local de tecnologías más avanzadas requirió importantes equipos de ingeniería especializada en adaptar las escalas de producción y en integrar la producción que estaba orientada a un mercado doméstico reducido y fuertemente protegido. La trayectoria de su aprendizaje trazaba un camino idiosincrásico muy distinto al clima competitivo de los países desarrollados, con lo cual no se traducía en la posibilidad de alcanzar mayores niveles de competitividad internacional. Es decir que, a pesar de que las firmas debían actuar en el medio local desplegando esfuerzos de adaptación que requerían el uso intensivo de tecnologías, estos esfuerzos conllevaban deseconomías estáticas y dinámicas tanto en lo que respecta a las escalas de producción como a la división del trabajo.

Estas condiciones fueron las causantes del agotamiento paulatino del mercado interno en la medida 
en que se fue absorbiendo la demanda excedente. Al mismo tiempo, el importante progreso técnico introducido se traducía necesariamente en la posibilidad de crear ventajas comparativas dinámicas para operar en los mercados internacionales, fuera de que la propia estructura industrial había llegado a un techo en su capacidad de generar incrementos en el empleo y en la productividad.

Simultáneamente, en las sociedades de mayor industrialización se estaba gestando el paso a un nuevo paradigma tecnoproductivo, cuyos modelos de organización de la producción industrial incorporaban una lógica muy distinta de la de los modelos de producción masiva fordista prevalecientes. Uno de los elementos claves que viabilizaron este cambio fue el extraordinario desarrollo de la microelectrónica, que permitió pasar del "mundo de lo electromecánico" al "mundo de lo electrónico". En contraposición, ante las dificultades de recrear el dinamismo industrial en la sociedad argentina, la respuesta local no fue la de avanzar en el sentido de aprovechar el acervo tecnológico acumulado en la etapa anterior, superando sus dificultades, sino la de un intento de reforma estructural asociada a la apertura de la economía. Sin embargo, el fracaso de su instrumentación en el período 1976-1981 concluyó con un proceso de desarticulación productiva.

Dentro de este marco, no es extraño que a partir de 1976 se modificara sustancialmente el flujo de inversiones directas. Prácticamente desaparecieron las nuevas inversiones del escenario industrial, siendo frecuente el cierre y repliegue de algunas firmas importantes, ${ }^{1}$ y gran parte de las nuevas inversiones se concentraron en el área financiera y en el sector petrolero. El contexto de apertura económica del período 1978-1981, la crisis y estancamiento del sector industrial, el acceso preferencial de las firmas locales a la promoción industrial en los pocos sectores dinámi$\cos$, los problemas de endeudamiento externo y el contexto global de incertidumbre e inestabilidad macroeconómica son algunos de los aspectos centrales que explican la pérdida de participación del capital extranjero en la industria argentina. ${ }^{2}$

A partir de mediados de los años ochenta se ve-

\footnotetext{
1 Durante este período se retiraron del país varias de las principales ETs, entre las que se destacan General Motors, Citroën, Chrysler, Peugeot, Squibb, Olivetti y otras.

2 La participación de las empresas extranjeras según el Censo de 1984 era del $26.8 \%$ de la producción, mientras una década atrás superaba el 32\%. (Sourrouille, Kosacoff y Lucángeli, 1985; Kosacoff y Azpiazú, 1989, y Azpiazú 1992).
}

rifica una cantidad importante de procesos de inversión que denota un nuevo dinamismo en el escenario doméstico, que a su vez resulta en el incremento de su participación en la estructura industrial. Este comportamiento no se difundió en todo el tejido industrial, sino que se concentró en especial en las actividades manufactureras asociadas al aprovechamiento de los recursos naturales (agroindustrias, petróleo, petroquímica, cemento, etc.), y en la reestructuración del complejo automotor. En las plantas industriales de las subsidiarias de las ETs se hicieron importantes transformaciones, que resultaron en un fuerte incremento de su productividad. La eliminación del sobreempleo, la racionalización de las líneas de producción, la realización de importantes cambios en la organización, asociados a la desincorporación de tecnologías, son algunos de los rasgos que permitieron este comportamiento. Sin embargo, en la medida en que a estos cambios no acompañó una difundida reestructuración de los equipamientos ya amortizados y muy lejanos de las prácticas internacionales, en particular por sus rasgos idiosincrásicos en cuanto a escala de producción y especialización, orientados a un mercado interno reducido y cerrado, a finales de la década de 1980 estos cambios se revelaron insuficientes frente a una economía en transformación, en particular en relación con su inserción externa.

\section{El escenario de los años noventa}

En la década de 1980 las condiciones macroeconómicas fueron el eje articulador de un escenario que se caracterizó por sus dificultades, las que llegaron a su punto más crítico con los episodios hiperinflacionarios de 1989 y 1990. En forma simultánea, durante ese período se dieron tres elementos que fueron el punto de apoyo de la nueva presencia del capital extranjero en la economía argentina en la década de 1990. El primero de ellos se vincula con la propia dinámica de la solución del endeudamiento externo, en la cual la capitalización fue el instrumento de financiamiento privilegiado para las nuevas inversiones y los procesos de privatización de empresas del Estado. El segundo se refiere a la consolidación de los grupos económicos nacionales, que como agentes de la industrialización son organizaciones muy diferentes de la típica empresa familiar de la etapa de sustitución de las importaciones, y que serán fundamentales en la articulación de acuerdos con las ETs para proyectos específicos. Finalmente, la notable expansión de la frontera de recursos naturales en el período 1970-1990 (gasífe- 
ros, pesqueros, cultivos oleaginosos, forestales, entre otros), que en contraposición con su virtual estancamiento en las cuatro décadas anteriores, generó, en un contexto de economía abierta, el retorno a una mayor especialización del país en producciones que hacen uso intensivo de esos recursos.

Estos cambios están influyendo en las decisiones de las ETs referidas a su participación en el país. En la actualidad se evidencian comportamientos y tendencias muy disímiles, pero la resultante final es una participación más activa de la inversión extranjera directa en relación con la observada en las dos décadas pasadas. La fusión y la relocalización internacional de empresas, la compra de firmas, el cierre de algunas plantas, la reorientación hacia actividades de ensamblaje y comerciales en detrimento de las industriales, la nueva relación entre el sistema financiero y el sector manufacturero, entre otros, son hechos cotidianos cuyas tendencias contrapuestas aún es difícil de sistematizar. En un contexto de profundas transformaciones económicas y de reinserción internacional, articulada entre el proceso de apertura y el de consolidación del
Mercosur, algunos de los elementos más destacados, que se analizarán más adelante, son la difusión de formas de globalización con la participación manufacturera de la filial local; la importancia de la capitalización de la deuda y del proceso de privatizaciones; la adopción de distintas modalidades de asociación entre las empresas; los recursos naturales como factor "clave", y el nuevo marco regulatorio para el capital extranjero.

En el caso particular de la capitalización de la deuda, ésta no sólo se impuso como uno de los mecanismos que permitieron resolver la dinámica del endeudamiento, sino que también se convirtió en uno de los instrumentos financieros privilegiados en la nueva estrategia de las ETs. En el segundo quinquenio de la década de 1980, ochenta y dos ETs utilizaron diferentes mecanismos de capitalización de deuda para financiar distintos procesos de inversión por $660 \mathrm{mi}$ llones de dólares (Fuchs, 1990). En particular se concentraron en el sector industrial, destacándose distintos proyectos en las áreas alimentaria, automotriz, petrolera y de productos químicos (cuadro 1).

CUADRO 1

Argentina: Capitalización de deuda externa por parte de empresas de capital extranjero

(Miles de dólares)

\begin{tabular}{|c|c|c|c|c|}
\hline Empresa & Sector de actividad & Régimen $^{a}$ & $\begin{array}{l}\text { País de } \\
\text { origen }\end{array}$ & $\begin{array}{r}\text { Miles de } \\
\text { dólares }\end{array}$ \\
\hline Swift-Armour S.A. & Frigorífico & $\mathrm{psc} / \mathrm{cdp}$ & EE.UU. & 138018.7 \\
\hline Transax S.A. & Autopartes & cdp & EE.UU. & 56020.4 \\
\hline La Isaura S.A. & Petrolera & cdp & España & 50118.5 \\
\hline Louis Dreyfus y Cía. Ltda. S.A. & Exportac. cereales y oleag. & $\mathrm{cdp}$ & Suiza & 35030.5 \\
\hline Maltería Pampa S.A. & Elaboración malta & $\operatorname{cdp}$ & Brasil & 33748.0 \\
\hline Renault Argentina S.A. & Automotriz & cdp & Francia & 28189.6 \\
\hline Cervecería Río Paraná S.A. & Cervezas & $\mathrm{cdp}$ & Bélgica & 24425.9 \\
\hline Dow Química Argentina S.A. & Productos químicos & cdp & EE.UU. & 13027.4 \\
\hline Autolatina Argentina S.A. & Automotriz & $\mathrm{cdp}$ & EE.UU. & 12790.7 \\
\hline Syntex S.A. & Productos químicos & psc & EE.UU. & 11872.2 \\
\hline Cía. Embotella. Argentina S.A. & Bebidas s/alcohol & psc & EE.UU. & 11765.0 \\
\hline GTE Silvania S.A. & Tubos y lámparas fluoresc. & cdp & EE.UU. & 11325.3 \\
\hline Pepsi Cola Argent. S.A. & Bebidas s/alcohol & psc & EE.UU. & 9800.0 \\
\hline Saab-Scania Argent. S.A. & Automotriz & cdp & Suecia & 9661.9 \\
\hline Parafina del Plata S.A. & Aceites lubricantes & cdp & Suiza & 9573.1 \\
\hline Pirelli S.A. Platense & Neumáticos & psc & Italia & 9571.4 \\
\hline Coca Cola S.A. & Bebidas s/alcohol & cdp & EE.UU. & 9383.0 \\
\hline Kodak Argentina S.A. & Aparatos fotográficos & psc/on & EE.UU & 9370.9 \\
\hline Banco Beal S.A. & Banco & psc & Bélgica & 8407.8 \\
\hline Abbott Laboratorios S.A. & Laborat. medicinal & psc & EE.UU. & 7500.0 \\
\hline Shell S.A. & Petrolera & on & P. Bajos & 7499.8 \\
\hline Estab. Mecán. Jeppener S.A. & Metalmecánica & $\operatorname{cdp}$ & Italia & 7196.7 \\
\hline NCR Argentina S.A. & Maquinaria contabilidad & psc & EE.UU. & 7100.0 \\
\hline Lucas Indiel S.A. & Autopartes & cdp & Inglaterra & 6560.1 \\
\hline Suchard Argentina S.A. & Golosinas & $\mathrm{psc}$ & Suiza & 6469.2 \\
\hline H.F. Fuller Arg. S.A.I.C, & Adhesivos & cdp & EE.UU. & 6422.0 \\
\hline Equitel S.A. & Telecomunicaciones & on & Alemania & 6400.0 \\
\hline Compañía Argentina de Té & Producción de té & cdp & Bélgica & 6011.2 \\
\hline Carrefour Argentina S.A. & Supermercado & psc & Francia & 5170.8 \\
\hline
\end{tabular}


CUADRO 1 (continuación)

\begin{tabular}{|c|c|c|c|c|}
\hline Empresa & Sector de actividad & Régimen a & $\begin{array}{l}\text { País de } \\
\text { origen }\end{array}$ & $\begin{array}{r}\text { Miles de } \\
\text { dólares }\end{array}$ \\
\hline Productos Roche S.A. & Laborat. medicinal & psc & Suiza & 5000.0 \\
\hline Hughes Service S.A. & Servicios petroleros & psc & EE.UU. & 4594.8 \\
\hline Morgate Arg S.A. & Sin información & psc & $\ldots$ & 4548.7 \\
\hline Laborat. Glaxo Argent. S.A. & Laboratorio medicinal & $\operatorname{cdp}$ & Inglaterra & 4335.1 \\
\hline Ciba Geigy S.A.I.C. & Productos químicos & on & EE.UU. & 4268.3 \\
\hline Frig. Rioplatense S.A. & Frigorífico & psc & EE.UU. & 3990.0 \\
\hline Cargill S.A.C.I. & Industria alimentaria & cdp & EE.UU. & 3739.7 \\
\hline Cimet S.A. & Alambres, cables, cobre & psc & Alemania & 3692.6 \\
\hline Asgrow Argentina S.A. & Prod. semillas híbridas & psc & EE.UU. & 3500.0 \\
\hline Química Hoechst S.A. & Prod. químicos y farmac. & cdp & Alemania & 3260.6 \\
\hline Liquid Carbonic Arg. S.A. & Gases carbónicos & cdp & EE.UU. & 3166.7 \\
\hline Cía. Gillette S.A. & Hojas de afeitar & psc & EE.UU. & 3143.3 \\
\hline Neumáticos Good Year S.A. & Neumáticos & on & EE.UU. & 3000.0 \\
\hline Dycasa Arg. S.A. & Const. obras públicas & on & España & 3000.0 \\
\hline Cynamid Argentina S.A. & Productos químicos & psc & EE.UU. & 2986.8 \\
\hline Eaton S.A. & Autopartes & cdp & EE.UU. & 2488.9 \\
\hline Stauffer Química S.A. & Productos químicos & psc & EE.UU. & 2480.6 \\
\hline Aga Argentina & Gases comprimidos & psc & Suecia & 2076.9 \\
\hline Pioneer Argent. S.A. & Sin información & cdp & EE.UU. & 2001.8 \\
\hline Foxboro Argentina S.A. & Autopartes & psc & EE.UU. & 2000.0 \\
\hline Siemens S.A.I.C. & Telecomunicaciones & on & Alemania & 2000.0 \\
\hline Laborat. Phoenix S.A. & Laboratorio medicinal & psc & EE.UU. & 1969.4 \\
\hline Perkins Argent, S.A. & Autopartes & psc & EE.UU & 1928.5 \\
\hline Bausch y Lomb Argent. S.A. & Productos ópticos y científ. & psc & EE.UU & 1800.0 \\
\hline Hudson, Ciovini y Cía. S.A. & Bebidas alcohólicas & psc & Canadá & 1721.5 \\
\hline Arthur Martin S.A. & Fabric. cocinas y estufas & psc & Bélgica & 1573.9 \\
\hline Pittsburgh S.A. & Import. prod. químicos y metal. & psc & EE.UU. & 1510.0 \\
\hline Vitrofar S.A. & Envases de vidrio & on & EE.UU. & 1500.0 \\
\hline Banco Sudamericana S.A. & Herramientas & psc & Suecia & 1400.0 \\
\hline Mc Donalds Restaurantes & Servicios alimentarios & psc & EE.UU. & 1385.0 \\
\hline Punta del Agua S.A. & Sin información & cdp & $\ldots$ & 1357.8 \\
\hline Worthington Argent. S.A. & Bombas hidráulicas & psc & EE.UU. & 1177.0 \\
\hline Pond's Argent S.A. & Cosméticos & psc & EE.UU. & 1007.0 \\
\hline Elab. Arg. Cereales S.A. & Productos alimenticios & psc & EE.UU. & 1000.0 \\
\hline Semillas Interstate Arg. S.A. & Producción de híbridos & psc & EE.UU. & 1000.0 \\
\hline S.A. Nestlé & Golosinas & on & Suiza & 900.0 \\
\hline Boerhringer Argent. S.A. & Laboratorio medicinal & psc & Alemania & 842.5 \\
\hline Baker Transworld S.A. & Sin información & psc & EE.UU & 800.0 \\
\hline Rovafarm Argent. S.A. & Laborat medicinal & psc & Suiza & 789.2 \\
\hline Argenmilla S.A. & Agrícola-ganadera & psc & Italia & 756.3 \\
\hline Macusa & Curtiembre & psc & Italia & 750.0 \\
\hline Aerosol Filling Argent. S.A. & Productos químicos & psc & EE.UU. & 736.2 \\
\hline Fichet S.A. & Sin información & psc & Alemania & 445.4 \\
\hline Macrosa S.A. & Metalmecánica & psc & Italia & 321.3 \\
\hline Magate Arg. S.A. & Sin información & psc & $\ldots$ & 290.0 \\
\hline Quim. Arg. Houghton S.A. & Product. químicos indust. & psc & EE.UU. & 250.0 \\
\hline MTM S.A. & Telas metálicas & psc & Alemania & 230.7 \\
\hline Laborat. Upjohn S.A. & Laboratorio medicinal & psc & EE.UU. & 220.0 \\
\hline Cía. Sud. Kreglinger S.A. & Comercio mayorista & psc & Bélgica & 150.0 \\
\hline Fram Argentina S.A. & Autopartes & psc & EE.UU. & 123.0 \\
\hline Black y Decker Arg. S.A. & Herramientas & psc & EE.UU & 120.0 \\
\hline Dow Corning S.A. & Lubricantes y siliconas & psc & EE.UU. & 49.2 \\
\hline Citicorp Asesora S.A. & Servicios consultoría & psc & EE.UU. & 30.0 \\
\hline
\end{tabular}

Total

Fuente: Elaborado por el Area de Desarrollo Industrial de la CEPAL, Oficina en Buenos Aires, a base de información del Banco Central de la República Argentina.

\footnotetext{
a psc: capitalización deuda externa con seguro de cambio. cdp: capitalización deuda externa pública. on: on lending.
} 
A partir de 1991, la capitalización se articuló con el proceso de privatización de empresas estatales y adquirió una nueva dimensión, con un impacto estructural muy importante. Este fenómeno es uno de los ejes de las transformaciones que se están gestando en la sociedad argentina, principalmente en las áreas de las telecomunicaciones, el petróleo, la energía eléctrica, el transporte y los caminos, y en el área industrial, en los sectores siderúrgico, petroquímico y de astilleros (cuadro 2). Debe destacarse el alto nivel de participación de las transnacionales en este proceso (más de un $40 \%$ del valor patrimonial total de las empresas privatizadas pertenece a firmas de capital extranjero) (cuadro 3), así como el hecho inédito en el ámbito local de asociación entre estas firmas y un núcleo selecto de grupos económicos nacionales en la articulación de negocios específicos. En estas alianzas por lo general las ETs asumen el papel de "operadores técnicos", mientras que la gestión administrativa e institucional recae en las empresas locales. A su vez, estos consorcios se unen a entidades bancarias locales y extranjeras para formar "paquetes financieros". Además de la participación de ETs norteamericanas, se destaca la alta presencia de empresas españolas (en telecomunicaciones, transporte, energía, agua y gas), francesas (petróleo, energía, agua, siderurgia y telecomunicaciones), italianas (gas), chilenas (energía), y la ausencia de empresas de origen japonés. Dos rasgos distintivos de estas empresas son, por un lado, la presencia por primera vez en el país de la gran mayoría de ellas, y por otro, el hecho de que varias de ellas sean empresas estatales.

CUADRO 2

Argentina: Participación de las empresas extranjeras en las privatizacionesa (Porcentajes y millones de dólares)

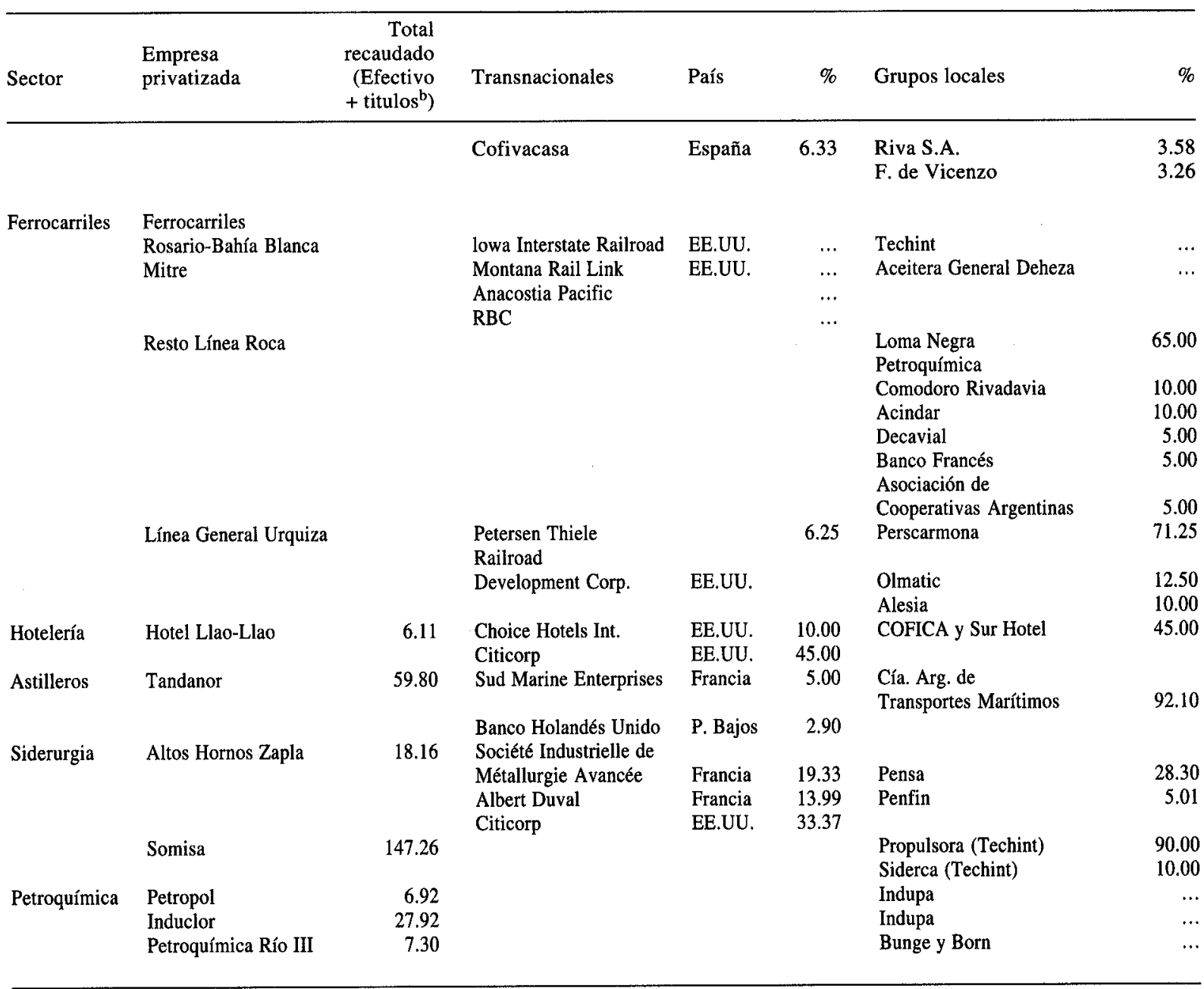


CUADRO 2 (continuación)

\begin{tabular}{|c|c|c|c|c|c|c|c|}
\hline Sector & $\begin{array}{l}\text { Empresa } \\
\text { privatizada }\end{array}$ & $\begin{array}{r}\text { Total } \\
\text { recaudado } \\
(\text { Efectivo } \\
+ \text { titulos }^{b} \text { ) }\end{array}$ & Transnacionales & País & $\%$ & Grupos locales & $\%$ \\
\hline & Polisur & 22.30 & & & & Garovaglio y Zorraquin & $\cdots$ \\
\hline & Monómeros vinílicos & 14.60 & & & & Viniclor & ... \\
\hline \multirow[t]{29}{*}{ Petróleo } & & & & & & & \\
\hline & Tordillo & 179.09 & $\begin{array}{l}\text { Santa Fe Energy } \\
\text { Energy }\end{array}$ & EE.UU. & 20.00 & Techint & 47.50 \\
\hline & & & Development Corporation & EE.UU. & 12.50 & Pérez Companc & 20.00 \\
\hline & El Huemul - Koluel & 170.48 & Total austral & Francia & 10.00 & & \\
\hline & Puesto Hernández & 286.35 & Oxy & EE.UU. & 40.50 & $\begin{array}{l}\text { Pérez Companc } \\
\text { Otros }\end{array}$ & $\begin{array}{r}57.00 \\
2.50\end{array}$ \\
\hline & Vizcacheras & 167.69 & Repsol & España & 50.00 & Astra & 50.00 \\
\hline & Santa Cruz I & 55.00 & $\begin{array}{l}\text { Quintana Petroleum } \\
\text { Marc Rich }\end{array}$ & $\begin{array}{l}\text { EE.UU. } \\
\text { Suiza }\end{array}$ & $\begin{array}{l}28.56 \\
25.00\end{array}$ & Soldati & 46.44 \\
\hline & Tierra del Fuego & 143.50 & $\begin{array}{l}\text { Chavuco Resources } \\
\text { Coastal Argentina }\end{array}$ & $\begin{array}{l}\text { Canadá } \\
\text { EE.UU. }\end{array}$ & $\begin{array}{l}33.34 \\
14.29\end{array}$ & Bridas & 52.37 \\
\hline & Santa Cruz II & 141.60 & & & & Inter Río Holding Establishment & 20.00 \\
\hline & & & & & & Astra & 40.00 \\
\hline & & & & & & Pérez Companc & 40.00 \\
\hline & Palmar Largo & 36.00 & Norcen Int. Ltd. & Canadá & 25.50 & Macri & 29.00 \\
\hline & & & Dong Won Co. Ltd. & Corea & 20.00 & Soldati & 25.50 \\
\hline & Aguaragüe & 143.70 & Ampolex & Australia & 35.71 & Techint & 35.72 \\
\hline & & & Petrobras & Brasil & 21.43 & Soldati & 7.14 \\
\hline & Refinaria Campo Durn & 64.10 & & & & Isaura & 15.01 \\
\hline & & & & & & Pérez Companc & 39.99 \\
\hline & & & & & & $\begin{array}{l}\text { Macri } \\
\text { Astra }\end{array}$ & 30.00 \\
\hline & Ebytem S.A. & 19.04 & & & & Isaura & 100.00 \\
\hline & Destilería Dock Sud & 11.71 & & & & Soldati & 100.00 \\
\hline & Planta de Aerosoles & 1.62 & & & & Superservicios (Beraldi) & 100.00 \\
\hline & Oleoductos Troncales & 77.05 & & & & Pérez Companc & 33.00 \\
\hline & & & & & & Bolland & 20.00 \\
\hline & & & & & & Bridas & 17.00 \\
\hline & & & & & & Macri & 19.00 \\
\hline & & & & & & Astra & 10.00 \\
\hline & & & & & & Techint & 3.00 \\
\hline & Destilería San Lorenzo & 12.21 & & & & Pérez Companc & 56.49 \\
\hline & & & & & & Soldati & 42.51 \\
\hline \multirow{16}{*}{ Gas } & Gas del Estado & & & & & & \\
\hline & $\begin{array}{l}\text { Transportadora de Gas } \\
\text { del Sur }\end{array}$ & 356.20 & $\begin{array}{l}\text { Enron Pipeline Company } \\
\text { Citicorp }\end{array}$ & EE.UU. & 25.00 & Pérez Companc & 25.00 \\
\hline & & & Equity Investments & EE.UU. & 25.00 & Argentina Private Development & 25.00 \\
\hline & $\begin{array}{l}\text { Transportadora de Gas } \\
\text { del Norte }\end{array}$ & 210.22 & $\begin{array}{l}\text { Novacorp International } \\
\text { Transcogas }\end{array}$ & $\begin{array}{l}\text { Canadá } \\
\text { Canadá }\end{array}$ & $\begin{array}{l}25.00 \\
36.00\end{array}$ & Techint & 39.00 \\
\hline & Distribuidora de Gas & 300.02 & British Gas & G. Bretaña & 41.00 & Pérez Companc & 25.00 \\
\hline & Metropolitana & & & & & Astra & 20.00 \\
\hline & & & & & & Invertrad (Acindar) & 14.00 \\
\hline & Distribuidora de Gas & 155.55 & Manra & España & 21.00 & Soldati & 28.00 \\
\hline & Buenos Aires Norte & & Gas Natural & España & 51.00 & & \\
\hline & $\begin{array}{l}\text { Distribuidora de Gas } \\
\text { Pampeana }\end{array}$ & 235.41 & Camuzzi Gasometri & Italia & 100.00 & & \\
\hline & Distribuidora de Gas & 103.60 & Tractebel & Bélgica & 40.00 & Garovaglio y Zorraquin & 20.00 \\
\hline & Litoral & & Iberdrola & España & 20.00 & Diecisiete de Abril (Bemberg) & 20.00 \\
\hline & $\begin{array}{l}\text { Distribuidora de Gas } \\
\text { Centro }\end{array}$ & 138.00 & Società Italiana per il Gas & Italia & 25.00 & Macri & 75.00 \\
\hline & $\begin{array}{l}\text { Distribuidora de Gas } \\
\text { Cuyana }\end{array}$ & 122.00 & Società Italiana per il Gas & Italia & 25.00 & Macri & 75.00 \\
\hline & Distribuidora de Gas & 72.03 & & & & Cartellone & 40.00 \\
\hline & Noroeste & & & & & $\begin{array}{l}\text { Banco Francés } \\
\text { Cía. de Consumidores de Gas } \\
\text { de Santiago }\end{array}$ & 20.00 \\
\hline
\end{tabular}


CUADRO 2 (continuacion)

\begin{tabular}{|c|c|c|c|c|c|c|c|}
\hline Sector & $\begin{array}{l}\text { Empresa } \\
\text { privatizada }\end{array}$ & $\begin{array}{r}\text { Total } \\
\text { recaudado } \\
(\text { Efectivo } \\
\left.+ \text { titulos }^{\mathrm{b}}\right)\end{array}$ & Transnacionales & País & $\%$ & Grupos locales & $\%$ \\
\hline Gas & $\begin{array}{l}\text { Distribuidora de Gas } \\
\text { del Sur }\end{array}$ & 148.03 & Camuzzi Gasometri & Italia & 100.00 & & \\
\hline \multirow[t]{29}{*}{$\begin{array}{l}\text { Energía } \\
\text { eléctrica }\end{array}$} & SEGBA & & & & & & \\
\hline & Central Costanera & 90.10 & $\begin{array}{l}\text { Endesa } \\
\text { Distribuidora }\end{array}$ & Chile & 50.01 & Pérez Companc & 12.50 \\
\hline & & & Chilectra Metropolitana & Chile & 5.00 & Inter Río Holding Establishment & 12.50 \\
\hline & & & $\begin{array}{l}\text { Enersis } \\
\text { Costanera }\end{array}$ & Chile & 15.00 & & \\
\hline & & & Power Electricidad & EE.UU. & 4.99 & & \\
\hline & Central Puerto & 92.21 & $\begin{array}{l}\text { Chilectra Quinta Región } \\
\text { Distribuidora Eléctrica }\end{array}$ & Chile & 17.50 & & \\
\hline & & & Quinta Región & Chile & 82.50 & & \\
\hline & Edenor & 427.00 & Electricité de France & Francia & 20.00 & Astra & 40.00 \\
\hline & & & $\begin{array}{l}\text { Endesa } \\
\text { Emp. Nacional Eléctrica }\end{array}$ & España & 10.00 & & \\
\hline & & & $\begin{array}{l}\text { del Ribagorzana } \\
\text { Société d'Aménagement }\end{array}$ & España & 20.00 & & \\
\hline & & & Urbain et Rural & Francia & 10.00 & & \\
\hline & Edesur & 511.01 & PSI Energy Inc. & EE.UU. & 10.00 & Pérez Companc & 40.50 \\
\hline & & & Enersis & Chile & 19.50 & & \\
\hline & & & $\begin{array}{l}\text { Endesa de Chile } \\
\text { Distribuidora }\end{array}$ & Chile & 10.00 & & \\
\hline & & & Chilectra Metropolitana & Chile & 20.00 & & \\
\hline & Central Alto Valle & 22.10 & Dominion Energy Inc. & EE.UU. & 60.00 & $\begin{array}{l}\text { Coop. Prov. de } \\
\text { Serv. Públicos (Neuquén) }\end{array}$ & 40.00 \\
\hline & Central Güemes & 86.20 & $\begin{array}{l}\text { Duke Güemes } \\
\text { TEW Americas }\end{array}$ & EE.UU. & 25.00 & Soldati & 25.00 \\
\hline & & & Development & EE.UU. & 15.00 & & \\
\hline & & & $\begin{array}{l}\text { Iberdrola } \\
\text { The Argentina }\end{array}$ & España & 20.00 & & \\
\hline & & & Investment $\mathrm{Co}$. & Is. Caimán & 15.00 & & \\
\hline & Pedro de Mendoza & 8.55 & & & & Acindar & 74.97 \\
\hline & & & & & & Massuh & 25.03 \\
\hline & Dock Sud & 25.00 & & & & Polledo & 100.00 \\
\hline & Edelap & 139.00 & Houston & & & & \\
\hline & & & Power Corporation & EE.UU. & 51.00 & Techint & 49.00 \\
\hline & Sorrento & 8.79 & & & & Malvicino & 17.97 \\
\hline & & & & & & Iate & 17.97 \\
\hline & & & & & & Eleprint & 3.98 \\
\hline & Ohras Sanitariac & & I yonnaice dec & & & Argon & 60.07 \\
\hline \multirow{5}{*}{ Agua } & Uoras saintartas & & Aux-Dumez & Francia & 3330 & Soldati & 20.70 \\
\hline & & & Compagnie & & & & 20.10 \\
\hline & & & Génèrale des Eaux & Francia & mas & Meller & 10.80 \\
\hline & & & Anglian Water & G. Bretaña & 4.50 & Banco Galicia & 8.10 \\
\hline & & & Aguas de Barcelona & España & 12.60 & & \\
\hline \multirow[t]{10}{*}{$\begin{array}{l}\text { Tele- } \\
\text { comunicaciones }\end{array}$} & Entel & & & & & & \\
\hline & Telefónica de Argentina & 749.01 & $\begin{array}{l}\text { Holding B.V. } \\
\text { (Telefónica) }\end{array}$ & España & 10.00 & Techint & 8.31 \\
\hline & & & Banco Central de España & España & 7.04 & Soldati & 5.00 \\
\hline & & & Banco Hispanoamericano & España & 5.00 & Pérez Companc & 14.56 \\
\hline & & & Republic New York & EE.UU. & 1.50 & & \\
\hline & & & Manufacturers Hannover & EE.UU. & 4.30 & & \\
\hline & & & $\begin{array}{l}\text { Bank of New York } \\
\text { Southel }\end{array}$ & EE.UU. & 4.16 & & \\
\hline & & & Equity Corporation & EE.UU. & 4.00 & & \\
\hline & & & Citicorp Venture Capital & EE.UU. & 20.00 & & \\
\hline & & & Bank of Zurich & Suiza & 4.16 & & \\
\hline
\end{tabular}


CUADRO 2 (continuación)

\begin{tabular}{|c|c|c|c|c|c|c|c|}
\hline Sector & $\begin{array}{l}\text { Empresa } \\
\text { privatizada }\end{array}$ & $\begin{array}{r}\text { Total } \\
\text { recaudado } \\
(\text { Efectivo } \\
\left.+ \text { titulos }^{\text {b }}\right)\end{array}$ & Transnacionales & País & $\%$ & Grupos locales & $\%$ \\
\hline \multirow{9}{*}{$\begin{array}{l}\text { Telecomu- } \\
\text { nicaciones }\end{array}$} & \multirow[t]{6}{*}{ Centro Bance } & o de Panamá & Panamá & 1.40 & & & \\
\hline & & & Vanegas & Panamá & 1.25 & & \\
\hline & & & Banco Atlántico & Panamá & 0.75 & & \\
\hline & & & Bank of Nova Scotia & Canadá & 0.10 & & \\
\hline & & & Arab Banking Co. & A. Saudita & 4.31 & & \\
\hline & & & Bank of Tokio & Japón & 4.16 & & \\
\hline & \multirow[t]{3}{*}{ Telecom } & 677.01 & Cable et Radio & Francia & 32.50 & Pérez Companc & 25.00 \\
\hline & & & J. P. Morgan & EE.UU. & 10.00 & & \\
\hline & & & Stet & & & Italia & 32.50 \\
\hline \multirow[t]{3}{*}{$\begin{array}{l}\text { Transporte } \\
\text { aéreo }\end{array}$} & \multirow{3}{*}{ Aerolíneas Argentinas } & 742.99 & Iberia & España & 47.50 & Amadeo Riva & 10.26 \\
\hline & & & Banco Hispanoamericano & España & 11.88 & Devi S.A. & 3.58 \\
\hline & & & Banesto & España & 11.88 & Medefin & 1.73 \\
\hline
\end{tabular}

Fuente: Elaboración propia sobre la base de información periodística y del Ministerio de Economía.

a Hasta febrero de 1993.

b Los títulos de la deuda se computan a su valor de mercado.

CUADRO 3

Argentina: Privatización por origen del capital de las empresas adjudicatarias y sectores de actividad

(Diciembre de 1992)

\begin{tabular}{|c|c|c|}
\hline \multirow{2}{*}{$\begin{array}{l}\text { Empresas adjudicatarias } \\
\text { / Sectores }\end{array}$} & \multicolumn{2}{|c|}{ Valor patrimonial ${ }^{\mathrm{a}}$} \\
\hline & Millones US\$ & $\%$ \\
\hline 1. Empresas nacionales & 4607.0 & 27.9 \\
\hline 2. Empresas extranjeras & 6821.2 & 41.3 \\
\hline \multirow{2}{*}{$\begin{array}{l}\text { 3. Estado nacional } \\
\text { Total }\end{array}$} & 5104.5 & 30.9 \\
\hline & 16532.7 & 100.0 \\
\hline a. Teléfonos & 3919.9 & 23.7 \\
\hline b. Aerolíneas & 874.1 & 5.3 \\
\hline c. Ferrocarriles & & \\
\hline d. Sector eléctrico & 3458.1 & 20.9 \\
\hline e. Puertos & 6.0 & 0.0 \\
\hline f. Caminos & & \\
\hline g. Televisión y radio & 13.9 & 0.1 \\
\hline h. Petróleo & 3500.1 & 21.2 \\
\hline i. Gas & 4065.9 & 24.6 \\
\hline j. Obras sanitarias & & \\
\hline \multirow{4}{*}{$\begin{array}{l}\text { k. Industria } \\
\text { - Petroquímica } \\
\text { - Talleres navales } \\
\text { - Acero }\end{array}$} & & \\
\hline & 260.9 & 1.6 \\
\hline & 59.8 & 0.4 \\
\hline & 199.4 & 1.2 \\
\hline 1. Inmuebles del Estado & 107.0 & 0.6 \\
\hline m. Otros & 67.6 & 0.4 \\
\hline
\end{tabular}

Fuente: Argentina, 1993, cuadros 8 y 9.

${ }^{a}$ Es el resultado financiero total computado como si se hubiera transferido el $100 \%$.

En relación con el marco regulatorio del capital extranjero, a diferencia del fuerte carácter restrictivo que caracterizó al tratamiento legal del capital extranjero durante la etapa de sustitución de importaciones, en la actualidad la legislación tiende hacia una filosofía de liberalización e incentivo para la radicación del inversionista extranjero. La legislación vigente en materia de inversiones extranjeras es la Ley 21382 (de 1976, con su texto ordenado en 1980) con las modificaciones introducidas por la Ley 23697 (de Emergencia Económica, de 1989) y el Decreto Reglamentario 1225/89. La ley de inversiones extranjeras (21382) supuso una liberalización sustancial en torno a la incorporación de inversión extranjera directa, así como en lo relativo a las actividades de las ETs en el país. La eliminación de todo tipo de prohibición en cuanto a sectores de destino, la igualdad de derechos y obligaciones respecto a los inversores nacionales y la supresión de todo tratamiento diferencial (acceso al crédito interno, recurrencia a regímenes de promoción, etc.), la posibilidad de invertir en bienes de capital usados y de capitalizar bienes inmateriales, la libre remisión de utilidades y repatriación de capitales, la consideración como relaciones entre "entes independientes" de aquellas que se establecen entre las casas matrices y sus subsidiarias locales son, entre otros, los rasgos más destacados de esta legislación que modifica totalmente la filosofía regulatoria y restrictiva predominante en los regímenes y antecedentes legales anteriores. Por su parte la Ley 23697 y el Decreto 1225/89 establecen la igualdad plena de derechos de las ETs respecto a las de capital nacional, al revocar el requerimiento de aprobación previa oficial que hasta entonces era necesario para efectuar determinadas inversiones (defensa, seguridad nacional, servicios públicos, energía, radiotelecomunicaciones, 
etc.). Consolidando esta actitud hacia el inversor extranjero, en el mes de noviembre de 1991 se firmó el Decreto 2428/91, por el cual la Argentina -primer país latinoamericano- adhiere al Convenio Consti- tutivo del Organismo Multilateral de Garantía de Inversiones (BM), eliminando toda posibilidad de restringir las operaciones de las firmas extranjeras en el país.

\section{III}

\section{Nuevas estrategias de las ETs industriales}

\section{en la Argentina}

En esta sección se describen los principales rasgos característicos del nuevo patrón de inserción de las ETs en la industria argentina en la década de 1990. Para ello se utilizó como base la información recogida en una encuesta realizada entre 61 de las principales subsidiarias de ETs industriales en la Argentina 3,4 . El eje articulador de esta caracterización son las estrategias que las filiales locales de ETs están aplicando con vistas a lograr una nueva forma de inserción en la economía local. Dentro del espectro de las ETs que desarrollan su actividad en el sector industrial se ha podido identificar tres tipos de firmas, de acuerdo con su estrategia de inserción.

$\square$ Empresas que basan su actividad manufacturera en la producción de bienes que hacen uso intensivo de recursos naturales y que cuentan con las ventajas competitivas que les otorgan estos bienes para competir internacionalmente.

$\square$ Empresas que, aprovechando la experiencia industrial adquirida durante la etapa de sustitución de importaciones, se insertan en los esquemas de globalización de la producción que tienen en marcha sus corporaciones, mediante la especialización en unos pocos bienes o partes destinados a la exportación y

3 La "Encuesta sobre las estrategias de las empresas de capital extranjero frente a los cambios estructurales, la globalización y la integración regional" fue realizada en forma conjunta por el Proyecto ARG. 91/019 Integración económica, PNUD - Subsecretaría de Estudios Económicos, Secretaría de Programación Económica, Ministerio de Economía y Obras y Servicios Públicos, y el Proyecto "La transformación del sistema económico argentino: industria y comercio internacional", financiado por la Fundación Volkswagen en la Oficina de la CEPAL en Buenos Aires.

4 Las 61 empresas que comprende la encuesta representan un 23\% de la facturación de las primeras 200 empresas industriales del país, y casi el $60 \%$ de las ventas de las primeras 100 subsidiarias de ETs industriales. En términos de comercio exterior, representaban el $8 \%$ de las exportaciones totales, el $12 \%$ de las exportaciones industriales, y el 13\% de las importaciones totales del país en 1991 (Bezchinky y Kosacoff, 1993). atienden la demanda interna con productos completamente importados, o bien de un fuerte contenido importado.

$\square$ Empresas que involucionan hacia esquemas en que el ensamblaje y la importación van adquiriendo importacia creciente frente a la producción local, en su estrategia de ocupación del mercado doméstico.

Estos tres tipos de estrategia definen un perfil que, si bien no ha consolidado aún su forma definitiva, difiere sustancialmente del que presentaban estas empresas en el período de sustitución de importaciones y tiene efectos importantes en la producción industrial, el comercio exterior, la innovación tecnológica y otros aspectos del modelo de desarrollo que se está gestando en el país.

\section{Mayor inserción en los mercados externos}

Un aspecto destacado de la dinámica renovada de las ETs industriales es el crecimiento de sus exportaciones. En el período de sustitución de importaciones, dado que el objetivo central de la presencia industrial de las ETs en la Argentina era abastecer el mercado interno, las exportaciones quedaban limitadas a las empresas cuya actividad se relacionaba con la explotación de recursos naturales. 5 En las nuevas condiciones, en cambio, si bien el mercado interno sigue siendo el objetivo prioritario, la exportación pasa a ocupar un lugar destacado para todas las ETs que continúan realizando actividades indus-

\footnotetext{
5 A mediados de los años setenta esta orientación presentó modificaciones sustantivas. Apoyados en su desarrollo local y en un generoso sistema de apoyo promocional, se verificó un importante incremento de las exportaciones industriales, fundamentalmente al área latinoamericana. Sin embargo, la interrupción de las condiciones locales que favorecieron ese fenómeno y la no transición hacia nuevas formas competitivas erosionaron rápidamente esa performance. Al respecto, véase por ejemplo Bisang, Kosacoff (1993).
} 
triales en el país. Si bien no hay datos que permitan evaluar la incidencia real de estas empresas en las exportaciones totales, se cuenta con algunos indicadores que reflejan el papel importante que tienen las exportaciones en la nueva estrategia de inserción local de estas firmas.

Según datos de la encuesta ya citada, las ventas al exterior se incrementaron más del $100 \%$ entre 1981 y 1992, con un especial dinamismo en el quinquenio 1986-1991, período en el cual crecieron a una tasa anual acumulativa del $15.8 \%$. Si bien a raiz del agotamiento de la sustitución de importaciones se crearon las condiciones para que todas las ETs radicadas en el país buscaran en mayor o menor medida la salida exportadora, los motivos de las distintas empresas y las características de su mayor inserción en los mercados externos difieren de acuerdo con su estrategia de reconversión. Mientras que en el caso de las empresas que operan dentro de esquemas de globalización el destino principal de los bienes son precisamente los mercados externos, en el de las empresas cuya actividad se relaciona con los recursos naturales su comportamiento depende en gran medida de los precios y condiciones del mercado internacional. Finalmente, para las firmas que siguen actuando dentro de la lógica de la sustitución de importaciones, la evolución de las ventas al exterior responde básicamente a un fenómeno relacionado con el ciclo económico interno más que a una nueva estrategia de inserción local. Es decir que la reactivación y la contracción del mercado interno afectarán en mucho mayor medida a las exportaciones de estas últimas que a las de las empresas que hacen uso intensivo de los recursos naturales, y en mucha menor medida a las empresas globalizadas. En el cuadro 4 se presentan datos de la encuesta que reflejan esta situación diferenciada.

\section{Mayor nivel de importaciones y cambio en su composición}

El modelo de sustitución de importaciones, durante cuya vigencia se produjo la industrialización de la Argentina, tuvo su eje en el establecimiento de industrias de bienes finales (básicamente bienes de consumo y algunos insumos intermedios), pero siguió dependiendo de la importación de gran cantidad de insumos, así como de bienes de capital. Las nuevas condiciones de apertura de la economía obligan a las ETs radicadas en el país a replantear
CUADRO 4

Argentina: Evolución de las exportaciones según estrategia de inserción de las empresas. 1981-1982

\begin{tabular}{lccc}
\hline Estrategia & \multicolumn{3}{c}{ Tasas de crecimiento anuales } \\
acumulativas (\%) \\
\cline { 2 - 4 } & $1981-1986$ & $1986-1991$ & $1991-1992$ \\
\hline Sustitutivas & 5.8 & 22.5 & -1.6 \\
Recursos naturales & -1.8 & 13.3 & -1.7 \\
Globalizadas & 3.6 & 16.7 & 5.2 \\
Total & -1.2 & 15.8 & -0.9 \\
\hline
\end{tabular}

Fuente: Elaboración a base de los datos de la encuesta efectuada en forma conjunta por el Proyecto ARG 91/019, "Integración económica", PNUD-Ministerio de Economía y Obras y Servicios Públicos, Secretaría de Programación Económica, y el Proyecto "La transformación del sistema económico argentino: industria y comercio internacional", financiado por la Fundación Volkswagen en la Oficina de la CEPAL en Buenos Aires.

su estrategia para abastecer el mercado local; tanto la importación de bienes finales que anteriormente producían en el país como la inclusión de mayores componentes importados en las funciones de producción, anteriormente vedados por las barreras comerciales y por las regulaciones sobre la integración nacional de la producción, son ahora posibilidades que todas las ETs están considerando en menor o mayor medida.

La encuesta en referencia aporta algunos datos sobre los cambios que se están produciendo en las importaciones. El primer hecho digno de destacar es el peso de las ETs en las importaciones totales; en 1992, las 61 empresas encuestadas importaron por un total de 1857 millones de dólares, equivalente a un $13 \%$ del valor de las compras totales de la Argentina en el exterior en ese año. Además, el análisis de las importaciones por tipos de bienes arroja también algunos resultados interesantes (cuadro 5). En primer lugar, resulta significativa la baja incidencia de las importaciones de bienes de capital, síntoma de la escasez de nuevas inversiones. Una explicación razonable de este fenómeno es que muchas de las inversiones de las ETs en la Argentina en los últimos años han correspondido a la compra de empresas o plantas existentes. Por otra parte, gran cantidad de firmas se encuentran aún en un período de transición, habiendo concentrado sus esfuerzos hasta el momento en la introducción de cambios en su organización o en mejoras puntuales que no implican la renovación del equipamiento físico de sus plantas en gran escala. 
CUADRO 5

Argentina: Estructura de las importaciones por tipo de bienes, 1991 y 1992

\begin{tabular}{lcr}
\hline \multirow{2}{*}{ Tipo de bienes } & \multicolumn{2}{c}{$\begin{array}{c}\text { Porcentaje sobre el } \\
\text { total }\end{array}$} \\
\cline { 2 - 3 } & 1991 & 1992 \\
\hline Insumos & 47.7 & 53.5 \\
Bienes de capital & 11.2 & 2.8 \\
Bienes finales para comercializar & 38.4 & 38.2 \\
Total & 100.0 & 100.0 \\
\hline
\end{tabular}

Fuente: Idem cuadro 4

En segundo lugar, la importancia de las importaciones de bienes finales para su comercialización (que representaron casi un $40 \%$ de las importaciones totales tanto en 1991 como en 1992) denota una de las características de la nueva forma de inserción de las ETs en la industria argentina, según la cual la comercialización de los productos importados de las respectivas corporaciones es tan importante como la producción industrial local, y en algunos casos mayor. Podría argumentarse que este peso de las importaciones de bienes finales para comercializar es coyuntural, debido a que las empresas no pudieron atender con su producción local la mayor demanda interna que significó la reactivación del mercado doméstico y, dada la apertura comercial, recurrieron a la importación como la fuente de abastecimiento más fácil y económica, aunque parece deberse a una tendencia más estructural. Este cambio se basa en el aprovechamiento integral de las redes comercial, de distribución, de financiamiento, de servicios posventa, marca, etc., que estas firmas se preocuparon de establecer durante décadas en la Argentina, lo que les facilita la comer- cialización de bienes finales importados. Finalmente, se destaca la importancia de los insumos importados, cuyo valor total se incrementó en un $40 \%$ entre 1991 y 1992 , lo que refleja también su creciente incidencia en las funciones de producción de estas empresas, que tiende hacia la pérdida de valor agregado local, a partir de procesos manufactureros que recurren con mayor intensidad al ensamblaje de partes importadas.

También el tipo de bienes importados varía de acuerdo con la estrategia de cada empresa. Se destaca la importancia que tienen para las empresas basadas en recursos naturales y para las adheridas al esquema de globalización las compras de insumos en el exterior, mientras que para las que continúan con la sustitución de importaciones tienen un peso prácticamente equivalente al de las compras de bienes finales destinados a la comercialización. Incluso en el caso de las empresas "globalizadas", el gran incremento de las importaciones de 1992 respecto de 1991, si bien se produjo tanto en las de insumos como en las de bienes finales, fue relativamente mayor en aquéllas. Estos datos son indicativos de la lógica diferente con que operan las distintas empresas (cuadro 6).

\section{Importancia del comercio intracorporativo}

Los grandes flujos de comercio internacional en el interior de las corporaciones transnacionales han sido uno de los elementos distintivos del patrón de intercambio comercial. Asimismo, una de las características principales del actual proceso de globalización es la creciente complementariedad entre la inversión extranjera directa y el comercio, y en particular el intracorporativo. Mientras que en la etapa anterior de expansión de las ETs a nivel mundial éstas se es-

CUADRO 6

Argentina: Importaciones por tipo de bienes según estrategia de inserción de las empresas, 1991 y 1992

(Miles de dólares y porcentajes sobre el total)

\begin{tabular}{|c|c|c|c|c|c|c|c|c|}
\hline \multirow[t]{2}{*}{ Estrategia } & \multicolumn{2}{|c|}{$\begin{array}{c}\text { Insumos } \\
(\%)\end{array}$} & \multicolumn{2}{|c|}{$\begin{array}{l}\text { Bienes de } \\
\text { capital (\%) }\end{array}$} & \multicolumn{2}{|c|}{$\begin{array}{c}\text { Bienes finales } \\
\text { para } \\
\text { comercializar }\end{array}$} & \multicolumn{2}{|c|}{$\begin{array}{c}\text { Total } \\
\text { (Miles de US\$) }\end{array}$} \\
\hline & 1991 & 1992 & 1991 & 1992 & 1991 & 1992 & 1991 & 1992 \\
\hline Sustitutivas & 49.3 & 48.4 & 5.4 & 5.1 & 45.3 & 46.5 & 481295.6 & 639057.2 \\
\hline Rec. naturales & 68.8 & 60.5 & 5.3 & 5.9 & 25.8 & 33.6 & 169033.0 & 194251.0 \\
\hline Globalizadas & 42.9 & 60.1 & 18.6 & 1.3 & 39.0 & 38.6 & 524797.5 & 1024442.0 \\
\hline Total & 49.0 & 56.6 & 11.5 & 3.0 & 39.5 & 40.4 & 1175126.1 & 1857750.2 \\
\hline
\end{tabular}

Fuente: Idem cuadro 4. 
tablecían en los distintos países como una alternativa al comercio para el abastecimiento de esos mercados, y producían los mismos bienes en distintas localizaciones, actualmente buscan racionalizar su estructura productiva global, especializando a sus distintas filiales en los distintos componentes de la producción internacionalizada. Una consecuencia directa de esta nueva forma de organización es la generación de importantes corrientes comerciales entre sus diversas filiales. Si bien no existen cifras que permitan evaluar con certeza la envergadura de este fenómeno, según muchos autores es uno de los aspectos principales del proceso de globalización, sobre todo por sus implicancias en la capacidad de aplicar políticas de los distintos Estados, en especial los de los países de menor desarrollo relativo (Dunning, 1992; Mortimore, 1992; Ostry, 1992; Vernon, 1992).

Los datos de la encuesta confirman la existencia del comercio intracorporativo, fenómeno que tiene en la Argentina extraordinaria relevancia. En efecto, casi el $60 \%$ de las exportaciones de estas empresas son en realidad transacciones intracorporativas, y lo mismo ocurre con casi el $80 \%$ de sus importaciones. Este es un indicador contundente, en un contexto de cambios importantes en la estrategia de las empresas transnacionales ante el paso de una economía fuertemente protegida a una economía abierta. La producción internacionalizada y las nuevas formas de globalización exigen la uniformación de los estándares de calidad de los productos y de los componentes y, por lo tanto, traen aparejado un cambio en la función de producción y en la composición de las importaciones de estas empresas. Donde anteriormente integraban el producto final con partes producidas en el país o con importaciones de diversa procedencia y calidad, en la actualidad deben importar los componentes que cumplan con las exigencias de calidad de la producción internacionalizada, lo cual se asegura fundamentalmente con la provisión intracorporativa de esas partes y componentes. El cuadro 7 muestra asimismo el incremento en el comercio intracorporativo en 1992 respecto del año anterior. Los datos del cuadro muestran también que, a pesar de su mayor inserción en los mercados externos, el saldo comercial de estas empresas es fuertemente negativo, y que

CUADRO 7

Argentina: Comercio exterior por tipo de transacción, 1991 y 1992 (Miles de dólares y porcentajes)

\begin{tabular}{|c|c|c|c|c|c|c|}
\hline \multirow[t]{2}{*}{ Rubro } & \multicolumn{2}{|c|}{ Intracorporativo } & \multicolumn{2}{|c|}{ Extracorporativo } & \multicolumn{2}{|c|}{ Total } \\
\hline & 1991 & 1992 & 1991 & 1992 & 1991 & 1992 \\
\hline Exportaciones & 495142.7 & 560108.0 & 463495.0 & 391174.0 & 958637.7 & 951282.0 \\
\hline$\%$ & 51.7 & 58.9 & 48.3 & 41.1 & 100.0 & 100.0 \\
\hline Importaciones & 822926.7 & 1455884.8 & 352199.4 & 401865.4 & 1175126.1 & 1857750.2 \\
\hline$\%$ & 70.0 & 78.4 & 30.0 & 21.6 & 100.0 & 100.0 \\
\hline Saldo comercial & -327784.0 & -895776.8 & 111295.6 & -10691.4 & -216488.4 & -906468.2 \\
\hline
\end{tabular}

Fuente: Idem cuadro 4.

el comercio intracorporativo tiene un papel decisivo en este fenómeno. Si bien el proceso de reconversión de las filiales de ETs no ha concluido, y su configuración final depende en gran medida del desarrollo del proceso de integración regional, parece claro que el patrón de comercio resultante es fuertemente deficitario. Aunque puede esperarse un incremento de las exportaciones de bienes producidos por empresas dedicadas a la explotación de recursos naturales y de partes fabricadas por empresas que trabajan dentro de esquemas de globalización de sus corporaciones, también es dable esperar aún un incremento de las importaciones por efecto de la profundización de los procesos de glo- balización y de la transformación de muchas empresas industriales en ensambladoras y representantes comerciales de sus casas matrices. Un cambio de esta tendencia supone importantes procesos de reconversión y de especialización exportadora, que necesariamente deberán estar articulados con importantes procesos de inversión en nuevas plantas industriales.

El comercio intracorporativo tiene también gran peso en la relación de las filiales de la corporación en el interior del Mercosur (cuadro 8). La particularidad que presenta este fenómeno es que dicho comercio es mayor aún que el comercio intracorporativo con el resto del mundo, lo cual indica que la 
diferencia en los niveles de desarrollo de la región y de los países centrales hace que las empresas deban recurrir en mayor medida a la red corporativa dentro del Mercosur para poder acceder a los estándares técnicos y de calidad que exige la producción internacionalizada.

CUADRO 8

Argentina: Estructura del comercio por origen / destino geográfico y por tipo de transacción, 1991 y 1992

\begin{tabular}{|c|c|c|c|c|}
\hline \multirow[t]{2}{*}{ Variable } & \multicolumn{2}{|c|}{ Origen/destino/tipo de transacción } & \multicolumn{2}{|c|}{$\begin{array}{c}\text { Porcentajes sobre el total } \\
\text { y miles de US\$ }\end{array}$} \\
\hline & & & 1991 & 1992 \\
\hline \multirow[t]{4}{*}{ Exportaciones (\%) } & Al Mercosur & Intracorporativo & 15.0 & 20.8 \\
\hline & & Extracorporativo & 11.0 & 8.4 \\
\hline & Al resto del mundo & Intracorporativo & 36.7 & 38.0 \\
\hline & & Extracorporativo & 37.3 & 32.7 \\
\hline Total (miles de US\$) & & & 958637.7 & 951282.0 \\
\hline \multirow[t]{4}{*}{ Importaciones (\%) } & Del Mercosur & Intracorporativo & 24.1 & 33.4 \\
\hline & & Extracorporativo & 4.1 & 4.9 \\
\hline & Del resto del mundo & Intracorporativo & 45.9 & 45.0 \\
\hline & & Extracorporativo & 25.9 & 16.7 \\
\hline Total (miles US\$) & & & 1175126.1 & 1857750.2 \\
\hline \multirow[t]{3}{*}{ Saldo (miles US\$) } & Del Mercosur & $\begin{array}{l}\text { Intracorporativo } \\
\text { Extracorporativo }\end{array}$ & $\begin{array}{r}-139645.9 \\
57462.3\end{array}$ & $\begin{array}{r}-421336.4 \\
-111418\end{array}$ \\
\hline & Del resto del mundo & Intracorporativo & $-188 \quad 138.1$ & -474440.4 \\
\hline & & Extracorporativo & 53833.3 & 450.4 \\
\hline Totales (miles US\$) & & & -216488.4 & -906468.2 \\
\hline
\end{tabular}

Fuente: Idem cuadro 4.

La estructura de comercio de las empresas varía también de acuerdo con su estrategia de inserción. En primer lugar, el comercio intracorporativo adquiere en el grupo de empresas globalizadas una relevancia que no tiene en los otros dos grupos. Así, en cuanto a sus exportaciones, mientras que el destino de casi la totalidad de ellas es la corporación, en los otros dos casos el valor de las transacciones de mercado es levemente mayor que el de las intracor- porativas. Por otra parte, en tanto que las exportaciones (sean intra o extracorporativas) de las empresas de los otros dos grupos decrecieron en 1992, las ventas intraempresa de las firmas globalizadas aumentaron mientras que sus ventas al exterior vía mercado disminuyeron (cuadro 9). Respecto de las importaciones, las transacciones intraempresa tienen una importancia decisiva tanto para las empresas que continúan en el esquema de sustitución como para

CUADRO 9

\section{Argentina: Exportaciones de la ETs por tipo de transacción y según estrategia de inserción, 1991 y 1992 \\ (Miles de dólares y porcentajes sobre el total)}

\begin{tabular}{|c|c|c|c|c|c|c|}
\hline \multirow[t]{2}{*}{ Estrategia } & \multicolumn{2}{|c|}{$\begin{array}{c}\text { Totales } \\
\text { (miles de US\$) }\end{array}$} & \multicolumn{2}{|c|}{$\begin{array}{c}\text { A la } \\
\text { corporación (\%) }\end{array}$} & \multicolumn{2}{|c|}{$\begin{array}{l}\text { Al resto del } \\
\text { mundo (\%) }\end{array}$} \\
\hline & 1991 & 1992 & 1991 & 1992 & 1991 & 1992 \\
\hline Sustitutivas & 178333.5 & 160786.0 & 37.4 & 41.5 & 62.6 & 58.5 \\
\hline Rec. naturales & 478175.0 & 402121.0 & 33.6 & 31.7 & 66.4 & 68.3 \\
\hline Globalizadas & 302129.2 & 388375.0 & 88.6 & 94.2 & 11.4 & 5.8 \\
\hline Total & 958637.7 & 951282.0 & 51.7 & 58.9 & 48.4 & 41.1 \\
\hline
\end{tabular}

Fuente: Idem cuadro 4. 
las globalizadas y mayor aún en este último caso. En cuanto a las empresas que se basan en la explotación de recursos naturales, las compras provenientes de la corporación son sólo levemente superiores al $50 \%$ del total.

En definitiva, el patrón de comercio exterior que presentan estas empresas es una manifestación de su nueva forma de inserción en la economía local. El alto peso de sus transacciones intracorporativas es un fenómeno muy diferente del que se registraba en el pasado, ya que si bien seguramente sus importaciones fueron siempre mayoritariamente intracorporativas, sus niveles actuales son mucho mayores, y su composición (con una gran incidencia de los bienes finales para comercializar y un peso marginal de los bienes de capital) es muy distinta. En cuanto a las exportaciones, en tanto, no sólo los niveles actuales son mucho mayores que los de la etapa de sustitución, sino que gran parte de esas ventas se canaliza a través de las redes corporativas, hecho que en el pasado sólo se verificaba en el caso de algunas exportaciones de productos agropecuarios o agroindustriales de bajo grado de elaboración, o en casos puntuales y aislados 6 .

\section{Importancia del Mercosur}

Frente al proceso de apertura de la economía, que elimina casi por completo el incentivo de las filiales locales de las ETs de producir para el mercado interno, el proceso de formación del Mercosur se ha con-
CUADRO 10

Argentina: Distribución de las líneas de producción según su escala relativa respecto de la flllal brasileña y el tipo de estrategia de la empresa

(Cantidad de líneas)

\begin{tabular}{lrrrrrr}
\hline Estrategia & $0-15 \%$ & $15-25 \%$ & $25-50 \%$ & $50-100 \%$ & $+100 \%$ & Total \\
\hline Sustitutivas & 1 & 6 & 8 & 10 & 5 & 30 \\
Rec. naturales & 2 & 1 & 4 & 4 & 1 & 12 \\
Globales & - & 2 & - & 2 & 2 & 6 \\
Total & 3 & 9 & 12 & 16 & 8 & 48 \\
\hline
\end{tabular}

Fuente: Idem cuadro 4.

vertido en uno de los puntos centrales del interés de esas empresas por continuar con sus actividades industriales en el ámbito local. Se trata de la formación de un gran mercado común que las ETs están en muy buenas condiciones para abastecer, dado que cuentan en general con filiales en los dos mercados principales (Brasil y Argentina), en los cuales ocupan posiciones de liderazgo. La mayoría de las ETs están tomando medidas para racionalizar y complementar sus actividades en ambos países, mientras que las que cuentan con filiales en uno solo de ellos están intentando formalizar acuerdos de complementación en materia de producción y comercio con otras empresas en la misma situación.

Contrariamente a la visión que se tiene sobre la distinta magnitud de los mercados argentino y brasileño y sobre la diferencia de escalas de producción que existe en distintos sectores industriales de esos

CUADRO 11

Argentina: Comercio exterior por origen/destino geográfico (Miles de dólares)

\begin{tabular}{|c|c|c|c|c|c|c|}
\hline \multirow[t]{2}{*}{ Rubro } & \multicolumn{2}{|c|}{ Mercosur } & \multicolumn{2}{|c|}{ Resto del mundo } & \multicolumn{2}{|c|}{ Total } \\
\hline & 1991 & 1992 & 1991 & 1992 & 1991 & 1992 \\
\hline Exportaciones & 249156.5 & 278159.0 & 709481.2 & 673123.0 & 958637.7 & 951282.0 \\
\hline$\%$ & 26.0 & 29.2 & 74.0 & 70.8 & 100.0 & 100.0 \\
\hline Importaciones & 331340.1 & 710637.2 & 843786.0 & 1147113.0 & 1175126.1 & 1857750.2 \\
\hline$\%$ & 28.2 & 38.3 & 71.8 & 61.8 & 100.0 & 100.0 \\
\hline Saldo comercial & -82183.6 & -432478.2 & -134304.8 & -473990.0 & -216488.4 & -906468.2 \\
\hline
\end{tabular}

Fuente: Idem cuadro 4.

6 Por ejemplo, el caso de IBM, que constituye una de las experiencias pioneras de inserción de filiales argentinas en procesos de producción internacionalizada. (Véase, por ejemplo Vispo y Kosacoff, 1991). dos países, según los datos de la encuesta en referencia, la situación es bastante diferente. En efecto, de las 48 líneas de producción para las cuales hay información sobre los dos países, 24 operan en la Argenti- 
na a una escala superior al $50 \%$ con respecto a las brasileñas ${ }^{7}$.

Mientras que la mayoría de estas líneas corresponde a producciones metalmecánicas o automotrices, las producciones vinculadas con la explotación de los recursos naturales se concentran en las 21 líneas que no tienen contraparte en Brasil (cuadro 10).

CUADRO 12

Argentina: Importancia del Mercosur dentro del comercio por grupo de ETs según estrategia de inserción, 1992

(Porcentajes sobre el total respectivo)

\begin{tabular}{lrr}
\hline Estrategia & Exportaciones & Importaciones \\
\hline Sustitutivas & 54.7 & 26.6 \\
Rec. naturales & 7.8 & 21.5 \\
Globalizadas & 40.9 & 48.7 \\
Total & 29.2 & 38.3 \\
\hline
\end{tabular}

Fuente: Idem cuadro 4.

Este hecho es sumamente importante a la hora de tomar decisiones en el interior de la corporación sobre la complementación de actividades en el ámbito del Mercosur. Hasta el momento no se sabe de ninguna ET que haya decidido abandonar definitivamente la producción industrial en el país, y ello obedece seguramente al hecho de que cuentan con instalaciones que no son tan marginales en cuanto a escala de producción (en especial a nivel regional), con una experiencia industrial acumulada, y con una serie de otros activos 8 que es posible aprovechar con vistas a tener presencia en el mercado zonal. Este mismo hecho influye seguramente en la decisión acerca de la incorporación de las filiales locales dentro de esquemas de globalización, dadas las exigencias de tecnología, escala y calidad de la producción internacionalizada.

La importancia del Mercosur para estas empresas se manifiesta también en los niveles de participación de esa zona en el comercio exterior de las mismas. Mientras que en 1991 el mercado zonal concentró casi el $30 \%$ de las exportaciones e importaciones de las empresas, en 1992 los porcentajes ascendieron a cerca del 30 y del 40 , respectivamente (cuadro 11).

7 De estos 24 casos, hay tres en los que las escalas son equivalentes, mientras que en ocho las argentinas son superiores a las brasileñas.

8 Mano de obra calificada, en algunos casos materias primas en condiciones favorables, entre otros.
CUADRO 13

Argentina: Importancia del comercio intracorporativo, total y con el Mercosur, por grupo de ETs según estrategia de inserción, 1992

(Porcentajes respecto del total respectivo)

\begin{tabular}{lccccc}
\hline \multirow{2}{*}{ Estrategia } & \multicolumn{2}{c}{ Exportaciones } & & \multicolumn{2}{c}{ Importaciones } \\
\cline { 2 - 3 } & $\begin{array}{c}\mathrm{Al} \\
\text { Mercosur }\end{array}$ & Totales & & $\begin{array}{c}\text { Del } \\
\text { Mercosur }\end{array}$ & Totales \\
\hline Sustitutivas & 47.5 & 41.5 & & 76.9 & 74.7 \\
Rec. naturales & 36.7 & 31.7 & & 68.9 & 53.8 \\
Globalizadas & 91.3 & 94.2 & & 92.2 & 85.3 \\
Total & 71.3 & 58.9 & & 87.2 & 78.4 \\
\hline
\end{tabular}

Fuente: Idem cuadro 4.

La tendencia en los próximos años será seguramente al incremento de esos niveles de participación, dado que la atención del mercado ampliado se encuentra en el centro de la estrategia de prácticamente todas las ETs.

La importancia del Mercosur varía también de acuerdo con la estrategia de las empresas, presentándose además situaciones diferenciadas para las exportaciones y las importaciones. En cuanto a las primeras, se destacan las empresas que continúan con el esquema de sustitución, para las cuales (si bien con montos relativamente reducidos) el mercado zonal es el destino de cerca del $60 \%$ de sus exportaciones (cuadro 12). Otro hecho destacado de este grupo de empresas es que dentro de las ventas a dicho mercado son levemente mayores las que se realizan fuera de la corporación que dentro de ella. Muy distinto es lo que ocurre entre las empresas globalizadas, donde el Mercosur como destino de las exportaciones tiene un peso relativo menor (aunque con montos mucho mayores), y las ventas externas intracorporativas son más del $90 \%$ del total (cuadro 13). Para las empresas dedicadas a la explotación de recursos naturales el Mercosur resulta totalmente marginal. En el caso de las empresas globalizadas, su acceso a los mercados internacionales se ve facilitado por el hecho de que actualmente operan cerca de la frontera técnica internacional, mientras que en el caso de las empresas que explotan los recursos naturales su acceso se basa en las ventajas comparativas de la producción primaria local.

Por el lado de las importaciones, el mercado zonal tiene gran importancia para las empresas globalizadas, que realizan cerca del $50 \%$ de sus compras externas en esa zona. Para las empresas que continúan dentro de la logica de la sustitución, tiene una importancia mucho menor ( $y$ fuertemente intracorpo- 
rativa), mientras que para las que se dedican a la explotación de recursos naturales, al igual que en el caso de las exportaciones, el mercado zonal resulta de una significación menor.

\section{Producción y tecnología}

La instalación de las ETs en la Argentina durante la etapa de sustitución de importaciones se caracterizó porque, dada la reducida dimensión de un mercado local altamente protegido, fue necesario adaptar las plantas a escalas de producción mucho menores que aquéllas para las cuales habían sido concebidas en los países de origen, y operar con un grado de integración mucho más elevado. El comportamiento tecnológico de esas empresas se basaba en la introducción de productos y procesos ya desarrollados en las sociedades más avanzadas, pero que requerían ser adaptados a las condiciones locales imperantes. Esta práctica demandó a las empresas un importante esfuerzo de ingeniería y de investigación y desarrollo, el que, sin embargo, desplegaron siguiendo un sendero muy localista y divergente del de las mejores prácticas internacionales.

CUADRO 14

Argentina: Distribución de las empresas según porcentaje de ventas que destinan a investigación y desarrollo, 1991

\begin{tabular}{lc}
\hline Porcentaje de las ventas & Cantidad de empresas \\
\hline Sin gastos de I y D & 9 \\
$0-1$ & 12 \\
$1-2$ & 12 \\
+2 & 6 \\
Total & 39 \\
\hline
\end{tabular}

Fuente: Idem cuadro 4.

Dado el nuevo escenario que enfrentan las ETs en la Argentina, en que las exigencias de inserción internacional son cada vez mayores, sin olvidar la presión competitiva que significa la integración en la red corporativa global, varias de estas empresas resolvieron encarar la incorporación de productos y procesos mucho más cercanos a la tecnología de vanguardia internacional. ${ }^{9} \mathrm{~A}$ raíz de este hecho se está dando la situación paradójica de que, si bien en las nuevas condiciones las empresas producirán con tecnologías más cercanas a las mejores prácticas internacionales, las necesidades de investigación y desarrollo y de ingeniería local serán mucho menores, debido a que estas técnicas, dada su mayor flexibilidad y la nueva dimensión en que colocan el problema de las economías de escala, y dada la posibilidad de incorporar un mayor contenido importado, pueden aplicarse localmente sin mayores modificaciones. Por otra parte, el perfil de la producción industrial futura de las filiales de ETs no justifica la realización de grandes gastos en IyD a nivel local, puesto que se tratará, en primer lugar, de bienes o partes fabricados con tecnología de punta y escala similar a la internacional, destinados a la exportación; en segundo lugar, de transformación de recursos naturales, para la cual también se puede acceder a tecnología de punta desarrollada en el exterior; y por último, de procesos de fabricación con un alto contenido de ensamblaje y un bajo nivel de integración local.

La encuesta en referencia ha recogido datos sobre el gasto en IyD de 39 empresas, el que asciende a un total de 32.6 millones de dólares para 1991, apenas el $0.1 \%$ de lo que las corporaciones respectivas destinaron para ese fin en ese mismo año. Este indicador evidencia los rasgos esenciales de la presencia tecnológico-industrial de las ETs en la Argentina. La participación de las filiales locales en los gastos de IyD son absolutamente marginales y proporcionalmente mucho menores que la ya escasa participación en las ventas del conjunto de la corporación. Es decir, las filiales locales acceden al conocimiento generado en los laboratorios de las sociedades desarrolladas, pero no tienen una intervención activa en la generación de innovaciones mayores. Todo su esfuerzo se concentra en actividades de adaptación, que a su vez tienden a reducirse en el nuevo contexto de la economía interna. Esto último queda de manifiesto en la escasa importancia que tienen los gastos en IyD en el valor total de las ventas de las filiales locales, que son muy inferiores a los valores medios de sus corporaciones. En efecto, en 1991 treinta y nueve subsidiarias locales destinaron el $1 \%$ del valor total de sus ventas a gastos en IyD. En la situación más extrema, nueve de estas empresas declararon no realizar este tipo de gastos, mientras que 24 no superaban el $2 \%$, y sólo seis firmas asignaron más del $2 \%$ de sus ventas a gastos de IyD (cuadro 14).

\footnotetext{
9 Si bien esto no se ha extendido a todo el conjunto de ETs radicadas en la Argentina, parece ser una tendencia que se difundirá entre las firmas que sigan desarrollando alguna actividad industrial a nivel local.
} 


\section{Posición marginal dentro de las respectivas corporaciones}

Una de las características reiteradamente señaladas en los trabajos sobre la inserción de las ETs en la industria argentina es el hecho paradójico de que, si bien a nivel local se encuentran entre las firmas líderes de los sectores en los que desarrollan su actividad, dentro de sus respectivas corporaciones resultan marginales (Sourrouille, Gatto y Kosacoff, 1984).

Esta característica se mantiene en la actualidad en lo que respecta a la incidencia de la facturación de las filiales locales en la corporación respectiva en su conjunto. Según datos de la encuesta citada, 45 de las 61 empresas proporcionaron información acerca de la facturación de sus corporaciones respectivas en 1991. Estas 45 firmas suman un total de ventas en la Argentina de 7118 millones de dólares en ese mismo año, lo que representa casi el $90 \%$ de las ventas de todo el padrón de la encuesta, y un $0.8 \%$ de las ventas totales de sus corporaciones respectivas (casi 848000 millones de dólares) en ese mismo año. Este primer indicador confirma que, en términos agregados, la importancia de las filiales locales dentro de sus redes corporativas sigue siendo marginal.

Veintiocho de estas empresas tienen un peso inferior al $1 \%$ en la facturación total de sus corporaciones. En estos casos no se observan rasgos característicos en cuanto al monto de facturación local de las empresas ni en cuanto a su estrategia de inserción. En sólo 17 empresas la facturación local es superior al $1 \%$ de las ventas totales de su corporación, y se ubican entre el 1.3 y el $3.2 \% 10$. En cuanto al empleo, sólo seis empresas tienen más del 5\% del empleo total de sus corporaciones respectivas. Sin embargo, con una sola excepción, se trata de empresas de escasa significación en el mercado local.

La comparación de las filiales locales con sus corporaciones en lo que respecta a escalas de producción arroja también algunos resultados dignos de mención. Si se considera la filial de mayor escala de producción, se cuenta con información sobre 59 líneas de producción pertenecientes a 28 empresas. Ocho de esas líneas se producen sólo en la Argentina, y se trata de productos derivados de la producción agropecuaria o bien de empresas cuya actividad a

10 Hay un solo caso de una empresa del rubro alimentario cuya facturación local representa el $47 \%$ del total de su corporación. Sin embargo, esto se debe a que la rama de actividad de esta firma a

\begin{tabular}{|c|c|c|c|c|c|c|c|}
\hline \multicolumn{8}{|c|}{$\begin{array}{l}\text { tiva den } \\
\text { de estra } \\
\text { (Cantidac }\end{array}$} \\
\hline \multicolumn{2}{|c|}{ Estrategia } & $0-5 \%$ & $5-10 \%$ & $10-20 \%$ & $20-50 \%$ & $+50 \%$ & Total \\
\hline \multirow{3}{*}{\multicolumn{2}{|c|}{$\begin{array}{l}\text { Sustitutivas } \\
\text { Rec. naturales } \\
\text { Globalizadas }\end{array}$}} & 6 & 7 & 11 & 4 & 2 & 30 \\
\hline & & 1 & 4 & 2 & $\ldots$ & 3 & 10 \\
\hline & & $\ldots$ & 5 & 2 & 3 & 1 & 11 \\
\hline \multicolumn{2}{|l|}{ Total } & 7 & 16 & 15 & 7 & 6 & 51 \\
\hline
\end{tabular}

Fuente: Idem cuadro 4.

nivel local no está relacionada con la actividad principal de la corporación respectiva. De las 51 líneas restantes que se producen tanto en la Argentina como en otras filiales de la corporación, la mayoría opera a escalas que se ubican entre el 5 y el $20 \%$ de las mayores a nivel de la corporación, sin que se registren en este caso diferencias de acuerdo con el tipo de estrategia local de las firmas (cuadro 15).

\section{Asociaciones y propiedad del capital}

Las publicaciones recientes sobre el nuevo dinamismo de las ETs en la escena internacional se refieren a las alianzas estratégicas como uno de los fenómenos más novedosos que presenta el panorama de fines de los años ochenta y principios de los noventa. En efecto, en los últimos años las ETs han formado entre ellas gran cantidad de alianzas en las áreas de producción, comercialización e incluso (lo que es más significativo) en áreas claves para su propia capacidad competitiva, como los proyectos de investigación y desarrollo. Entre las causas que se han mencionado para explicar este fenómeno (Mytelka, 1990; OCDE, 1991), impensable en la época de auge del sistema fordista de organización de la producción, se cuentan entre otras la necesidad de hacer frente a los costos crecientes de IyD y de inversión, la incertidumbre respecto del futuro y la complejidad que representa la convergencia de distintas tecnologías. 11

De cualquier manera, la ET ya no es vista como

nivel local es marginal dentro del total, y lo que se consignó como ventas de la corporación fue lo facturado dentro de ese rubro. En otros tres casos ubicados entre el 1 y el $3.2 \%$ se da una situación similar.

11 Microelectrónica, telecomunicaciones, biotecnología, nuevos materiales, y otras. 
una organización cuya importancia reside en la posesión y control de una gran cantidad de activos en distintas localizaciones, sino como el "sistema nervioso central" de una gran red internacional de capacidades productivas, tecnológicas, comerciales, financieras, etc., sobre la que no necesariamente ejerce el control mayoritario, pero que alimenta la capacidad competitiva de la corporación en forma "sistémica" (Dunning, 1992).

La formación de estas redes globales se ha concentrado fuertemente en lo que se ha dado en llamar la Tríada (Estados Unidos, la Comunidad Europea y Japón) (CET, 1991). Dentro de los países en desarrollo, sólo algunos del sudeste asiático participan de este fenómeno de manera importante, mientras que el resto sólo lo hace en forma marginal y en casos muy aislados.

En la Argentina se ha verificado en los últimos años la formación de gran cantidad de asociaciones entre ETs y empresas locales. Esto es, sin duda, un hecho novedoso para el medio local, en el cual dichas corporaciones siempre tuvieron un control accionario absoluto sobre sus filiales locales, pero se trata de asociaciones con características muy distintas de las alianzas estratégicas que se concentran a nivel de la Tríada. En primer lugar, son asociaciones cuyo objetivo central es la explotación de un negocio puntual que en general es marginal dentro de la respectiva corporación en su conjunto; en segundo lugar, la casi totalidad de estas asociaciones se concentra en las privatizaciones de empresas de servicios públicos; en tercer lugar, las pocas asociaciones que se registran en el sector industrial se llevan a cabo a través de la creación de nuevas empresas. Es así que, según los datos de la encuesta, de las 58 empresas que respondieron a esa pregunta, en 49 de ellas el capital extranjero participa con más del $90 \%$ (en 39 esa participación llega al 100\%). De las 9 restantes, sólo en 3 el capital extranjero tiene una participación inferior al 50\%.

\section{Dinamismo de las ETs en el mercado local}

En el período que comprende la década de 1970 y casi toda la década de 1980 , la inversión extranjera en la Argentina tuvo una dinámica muy diferente de la que había exhibido durante el auge del esquema de sustitución de importaciones. 12 Desde prin-

12 En particular, en la segunda fase de la industrialización sustitutiva de importaciones el sector industrial fue el motor de creci- cipios de los años setenta, cuando comenzó a hacerse evidente el agotamiento del modelo de industrialización basado en la sustitución de importaciones, se redujo la afluencia de inversiones extranjeras, tendencia que sólo se revirtió parcialmente durante la aplicación de la política de apertura entre 1976 y 1983, aunque con algunas características distintivas respecto del período anterior. Por un lado, los sectores privilegiados fueron esta vez el financiero y el petrolero, y por otro, la mayor afluencia de capitales extranjeros en ese período tuvo como contraparte la salida del país de algunas de las principales ETs industriales. 13

La disminución del ritmo de ingreso de inversiones extranjeras sólo se ha revertido en los últimos años, a partir de la puesta en marcha de una serie de reformas estructurales en el país, que tienden a constituir un modelo de economía abierta, con mucho menor injerencia del Estado en la actividad económica, y mucho más integrada al mundo. Además de la importante afluencia de inversiones extranjeras que ha significado el proceso de privatización de empresas del Estado, hay una corriente de nuevas inversiones en la industria.

CUADRO 16

Argentina: Evolución de las ventas de las empresas según estrategia de inserción, 1981-1992

\begin{tabular}{lrrr}
\hline Estrategia & \multicolumn{3}{c}{ Tasa de crecimiento anual } \\
& acumulativa (\%) \\
\cline { 2 - 4 } & $1981-1986$ & $1986-1991$ & $1991-1992$ \\
\hline Sustitutivas & 0.5 & 5.0 & 4.4 \\
Rec. naturales & -1.6 & 9.1 & 1.0 \\
Globalizadas & 2.6 & 11.7 & 11.6 \\
Total & -0.8 & 8.5 & 5.6 \\
\hline
\end{tabular}

Fuente: Idem cuadro 4.

Una de las facetas destacadas de la nueva dinámica de las ETs industriales es el incremento de sus ventas a partir de mediados de los años ochenta, lo

miento de la economía. En el período intercensal 1963-1973 la industria creció al $8 \%$ anual, y este dinamismo fue claramente impulsado por las subsidiarias de las ETs, que aumentaron su participación en el producto industrial del $15 \%$ en 1958 al $30 \%$ en 1973.

13 Según datos de los censos económicos nacionales, la participación de las ETs en el producto industrial que en 1973 era de $30.4 \%$ se redujo al $26.8 \%$ en 1984 . 
que les permitió recuperar, en un contexto de estancamiento industrial en la Argentina, las posiciones perdidas en la década anterior. Sin embargo, ese incremento no fue igual para todas las empresas (cuadro 16). Así destaca el dinamismo de las empresas que operan según esquemas de globalización, que se dio con particular intensidad a partir de mediados de los años ochenta, cuando la tasa de crecimiento anual acumulativa fue superior al $11 \%$, con lo cual este grupo de empresas que en 1981 concentraba el $20 \%$

\section{IV}

\section{Conclusiones}

A lo largo de este artículo se ha analizado una serie de hechos que evidencian el reciente dinamismo de las ETs y sus nuevas formas de inserción en la economía argentina, muy diferentes de las que presentaban en la etapa de sustitución de importaciones.

En relación con el patrón de comercio exterior, hay tres hechos destacables. En primer lugar, se verifican crecientes niveles de exportación, pero también niveles de importación mucho mayores, con el consiguiente incremento del comercio intraindustrial. Si bien la apertura de la economía fuerza a las empresas a redefinir su estrategia de inserción local, llevándolas a encarar programas de racionalización y de especialización, también funciona como incentivo para que esa especialización se haga sobre la base de un contenido importado mayor que en la etapa de sustitución y con una mayor orientación exportadora. En estas nuevas condiciones, las firmas que desarrollan su actividad en sectores vinculados con los recursos naturales son las que cuentan con mayores ventajas, dada la dotación de recursos del país, y también las empresas que se insertan en procesos de globalización, dado que son las que encaran el esfuerzo productivo con mayor orientación a los mercados internacionales. En segundo lugar, cabe destacar el fuerte peso del comercio intracorporativo, que confirma la tendencia que coinciden en señalar los estudios recientes sobre inversión y comercio a nivel internacional. En efecto, el $60 \%$ de las exportaciones y el $80 \%$ de las importaciones de estas empresas corresponden a transacciones intrafirma $y$, en tercer lugar, hay que señalar la importancia del Mercosur en el comercio de estas firmas, prueba de que han avanzado en el proceso de integración y complementación con las filiales en los de las ventas totales llegó a concentrar el $40 \%$ de ellas en 1992. Las empresas basadas en recursos naturales mostraron también gran dinamismo en sus ventas, si bien durante 1992 (año de reactivación del mercado interno) experimentaron un crecimiento de sólo $1 \%$. Las empresas que continúan dentro del esquema de sustitución crecieron a tasas menores, aunque importantes, que el resto de la industria en el período 1986-1991, pero las disminuyeron muy levemente en 1992. otros países de esa zona. Así, el 30\% de las exportaciones y el $40 \%$ de las importaciones se realizan dentro del mercado zonal. El comercio intracorporativo es especialmente importante en el caso de las importaciones y más acentuado con el Mercosur que con el resto del mundo, lo cual se explica por el hecho de que la producción internacionalizada requiere estándares técnicos y de calidad que sólo puede proveer la corporación, en especial dentro de los países del Mercosur.

En cuanto a la posición de las filiales locales de las ETs a nivel internacional, los datos con que se cuenta confirman que estas firmas conservan aún una de las características que presentaron desde su instalación en el país y que consiste en que a pesar de ser las empresas de mayor tamaño en el mercado local, su posición es marginal dentro de sus corporaciones respectivas, a punto tal que el promedio de ventas de las filiales encuestadas representa menos del $1 \%$ de las ventas de sus respectivas corporaciones. En cuanto al nivel tecnológico de las plantas locales de estas empresas, también se da la situación asimétrica de que aunque son las plantas más grandes y eficientes del medio local, están muy lejos en cuanto a tamaño y tecnología de los estándares alcanzados en los países desarrollados. Paradójicamente, si bien algunas empresas han reestructurado recientemente sus plantas en el país, lo que les permite acercarse más a la tecnología de vanguardia internacional (sobre todo en tecnologías de producto), utilizan tecnologías desarrolladas en los países centrales, que aplican directamente a la producción local, ahorrándose así el gran esfuerzo de ingeniería que requerían las tecnologías de la etapa de sustitución. Esto explica el bajo nivel 
de gastos en investigación y desarrollo de estas firmas, que oscila en torno al $1 \%$ de sus ventas y representa sólo el $0.1 \%$ de lo que sus respectivas corporaciones destinan a ese fin.

Se ha podido identificar cuatro tipos de ETs según la estrategia que sigan para adaptar sus estructuras empresariales locales a las nuevas condiciones, tanto internas como internacionales.

$\square$ Empresas que se insertan en los sectores de servicios, vinculados con el proceso de privatización, en asociación con grupos económicos locales. En general, la característica principal de estas asociaciones es que las empresas extranjeras asumen el papel de "operadores técnicos", mientras que los grupos locales se hacen cargo de la gestión administrativa e institucional del negocio, y los bancos locales y extranjeros forman el "paquete financiero". En este tipo de operaciones desempeña un papel central el mecanismo de capitalización de la deuda externa, que se ha utilizado como fuente de financiamiento privilegiada para estas inversiones. En este caso, la razón fundamental del interés de las ETs es que se trata de un negocio con una alta rentabilidad asegurada por altas tarifas y por la explotación en condiciones monopólicas en el mercado local, de áreas de especialización en bienes no comerciables con el exterior. Añádase a lo anterior los serios atrasos en el punto de partida de la provisión eficiente y global de servicios, que se caracterizan por la existencia de una demanda reprimida. Una señal clara del interés de las empresas transnacionales en este proceso es el hecho de que (excluida la reciente venta de Y.P.F.) algo más del $40 \%$ del valor patrimonial de las empresas privatizadas pertenece a firmas de capital extranjero.

Además de los efectos macroeconómicos de estas privatizaciones en las cuentas fiscales y en la distribución del ingreso (Guerchunoff y Cánovas, 1992), se plantea evaluar su impacto sobre la competitividad industrial, a partir de los efectos de derrame (spillovers) positivos que generen. Por una parte, deben medirse la mejor asignación de los recursos y la calidad y precio de los servicios y, por la otra, la inducción a la formación de proveedores y subcontratistas especializados que inicien una trayectoria competitiva que los haga viables simultáneamente como proveedores locales e internacionales.

$\square$ Empresas que desarrollan actividades vinculadas con el aprovechamiento de las ventajas que otorga la dotación de recursos naturales del país. Luego de más de cuatro décadas de estancamiento (entre 1930 y 1970), la frontera de recursos naturales de la Argentina ha experimentado en los últimos veinte años una importante expansión, impulsada por los cambios agrícolas (en particular la producción de soya), el descubrimiento de grandes reservas de gas y de nuevas explotaciones petroleras, el desarrollo forestal inducido por las desgravaciones impositivas, la explotación pesquera, y las perspectivas del área minera, aún en estado muy incipiente. A partir de esas nuevas posibilidades, cuyos encadenamientos con producciones de mayor valor agregado involucran la formación de redes productivas asociadas a procesos industriales, de comercialización, de transporte y de otros servicios, se verifica el mayor dinamismo y el mayor flujo de nuevas inversiones, en particular en los complejos agroindustrial, petroquímico y papelero. El fundamento de estas inversiones es la explotación de una ventaja natural del país con el doble objetivo de abastecer el mercado ampliado (Mercosur o América Latina en su conjunto) y exportar al mercado mundial. En este sentido, un ejemplo excelente es la activa presencia (en algunos casos de empresas de reciente incorporación) de prácticamente todas las grandes ETs productoras de alimentos del mundo, que han generado un clima de inversión y de compras -en muchos casos aún en gestación- en las empresas líderes de capital nacional.

$\square$ Empresas que se "globalizan". Este es el caso donde se produce el cambio más importante en la lógica industrial de las firmas radicadas en el país, que significa la difusión de las estrategias de globalización de las corporaciones transnacionales, en las cuales participa industrialmente la filial local. Si bien la atención del mercado local (ahora el mercado regional) sigue siendo la razón central de la presencia de estas firmas en el país, su estrategia industrial es muy distinta de la que seguían para la atención de un mercado interno protegido. En efecto, los bienes que comercializan en el mercado local o son completamente importados, o bien contienen en grado cada vez mayor un proceso de ensamblaje de componentes importados. Su producción industrial se desplaza hacia una pequeña gama de bienes o componentes que tienen como destino la exportación, en muchos casos realizada a través de los canales intracorporativos. Esta especialización se realiza con tecnologías cercanas a las más avanzadas internacionalmente, en plantas instaladas en los últimos años. La experiencia pionera de Saab Scania a finales de los años setenta en su planta de camiones, complementada con la filial brasileña, la reestructuración de la planta local de IBM a principios de los años ochenta para la produc- 
ción y exportación de impresoras y cintas (Vispo y Kosacoff, 1991); la reconversión de la industria automotriz, con mayor énfasis a fines del decenio de 1980, para especializarse en algunos núcleos de autopartes destinadas al mercado de exportación, y el fuerte incremento de las importaciones en su función de producción (Kosacoff, Todesca y Vispo, 1991) son algunos ejemplos que evidencian claramente la incipiente difusión de estrategias empresariales integradas en los procesos de globalización. Esta distinta forma de inserción internacional se refleja en una tendencia (dentro de un marco de permanente negociación con las autoridades económicas) a un balance comercial caracterizado por el comercio intraindustrial y la intensificación del comercio exterior.

$\square$ El resto de las ETs, que parecen no haber definido su estrategia y siguen funcionando dentro del esquema de sustitución de importaciones. Si bien las nuevas condiciones de apertura de la economía eliminan el incentivo que tuvieron históricamente estas empresas para producir localmente, en la práctica no hay constancia de que alguna de ellas haya resuelto dejar definitivamente el país. Unas estarán buscando un esquema de "globalización" en los casos en los que sea posible especializar su producción; otras se están convirtiendo en representantes de sus casas matrices para la comercialización de productos importados. En todos los casos, la tendencia es hacia una nueva función de producción, con mayor contenido importado en la fabricación local, complementada con un incremento de la comercialización de bienes finales importados. La formación del Mercosur es sin duda un incentivo para que estas empresas decidan mantenerse "a la expectativa", tratando de buscar algún esquema de reconversión que les permita aprovechar las instalaciones industriales que poseen (en muchos casos en más de un país) y avanzar hacia la especialización y la complementación, o los canales de comercialización que establecieron durante el período de sustitución, para abastecer el mercado ampliado con productos importados.

A partir de esta caracterización, las perspectivas que presenta el proceso de reestructuración de las ETs parecen entroncarse con un nuevo patrón de especialización de la industria argentina. En las actuales condiciones de apertura de la economía, el único sector industrial que mantiene importantes ventajas competitivas es el vinculado con la transformación de los recursos naturales, y en especial el agroalimentario y el petrolero-gasífero. Existen pocas dudas acerca de que éste es un sector con grandes posibilidades de crecimiento en los próximos años, aunque subsiste el interrogante acerca de si evolucionará hacia procesos con mayor valor agregado que permitan ofrecer productos de alta calidad tanto en el mercado local como en el exterior, o si, por el contrario, experimentará una involución hacia un esquema de mera exportación de materias primas o de productos con un grado mínimo de elaboración. Las políticas que se pongan en práctica a nivel regional para incentivar la producción de alimentos, con mecanismos de control y con estándares de calidad adecuados, son sin duda el elemento fundamental que decidirá la evolución futura de este sector, teniendo en cuenta el atractivo que el Mercosur presenta para las empresas tanto locales como transnacionales. Es en este campo donde el avance hacia la diferenciación y hacia mayores niveles de valor agregado local puede producir más efectos de derrame en el resto de la economía, en particular en cuanto a la incorporación de progreso técnico y al empleo. Criterios similares se pueden aplicar a las industrias derivadas del petróleo y el gas, el papel y la pesca, pero en estos casos la evolución futura dependerá de los ciclos del negocio a nivel internacional.

En cuanto a los sectores industriales cuya actividad no se basa en la transformación de recursos naturales, en especial el sector metalmecánico, el panorama es más incierto. El esquema de globalización, que requiere contar con un mercado interno con un mínimo de "masa crítica" que motive estas estrategias, parece estar dando importantes resultados en la producción de bienes de tecnología y calidad superiores y a escalas internacionales. Además, introducirá en el tejido industrial nuevas prácticas de organización y nuevos criterios de eficiencia que todavía no se han difundido. Pero estas prácticas aún están restringidas a algunas actividades (entre las que se destacan el caso de IBM y el proceso de transformación automotriz, basado en la especialización en algunas autopartes), y hasta ahora no se evidencian señales de su difusión generalizada al resto de las actividades.

En definitiva, se observa un nuevo contexto, de transición hacia un nuevo modelo de inserción de la economía argentina en el mundo, y por consiguiente, hacia una nueva forma de inserción de las ETS en el escenario local. Este escenario es completamente distinto del que presentaba el período de sustitución, por razones locales, regionales e internacionales. El proceso de compra, asociación y fusión de empresas en 
el que participan activamente las ETS es una de las manifestaciones de esta transición en la que estas em- presas tratan de adaptarse a las nuevas condiciones de funcionamiento de la economía argentina.

\section{Bibliografía}

Argentina, Ministerio de Economía y Obras y Servicios Públicos, Secretaría de Programación Económica, (1993): Argentina. Un país para invertir y crecer, Buenos Aires.

Azpiazú, Daniel (1992): Las empresas transnacionales en una economía en transición: la experiencia argentina en los años ' 80. Proyecto "La transformación del sistema económico argentino: industria y comercio internacional", Buenos Aires, Fundación Volkswagen/ Oficina de la CEPAL en Buenos Aires.

Bezchinsky, Gabriel y Bernardo Kosacoff (1993): Las estrategias empresariales en una economía en transformación: las filiales de empresas transnacionales frente a los desafíos del Mercosur y la globalización, Buenos Aires, mimeo.

Bisang R., B. Kosacoff (1993): Exportaciones industriales en una economía en transformación. Las sorpresas del caso argentino, 1974-1990. Documento de trabajo $\mathrm{N}^{\circ} 48$, Buenos Aires, CEPAL.

CET (Centro de las Naciones Unidas sobre las Empresas Transnacionales) (1991): World Investment Report 1991. The Triad in Foreing Direct Investment, Nueva York. Publicación de las Naciones Unidas, $\mathbf{N}^{\circ}$ de venta E.91.II.A.12.

(1992): World Investment Report 1992. Transnational Corporations as Engines of Growth, Nueva York. Publicación de las Naciones Unidas, $\mathrm{N}^{\circ}$ de venta E.92.II.A.19.

Dunning, John (1988): Explaining International Production, Londres, Unwin Hyman.

(1992), International direct investment patterns in the 1990s, Nueva York, mimeo.

Esser, Klaus (1992): Exigencias económicas y desafío a la política económica en América Latina en los años noventa, América Latina. Hacia una estrategia competitiva, Berlín, Instituto Alemán de Desarrollo.

Fuchs, Mariana (1990): Los programas de capitalización de la deuda externa argentina, (LC/BUE/R. 153), Buenos Aires, Comisión Economica para América Latina y el Caribe (CEPAL), junio.

Guerchunoff, Pablo y Guillermo Cánovas (1992): Privatizaciones: la experiencia argentina, Buenos Aires, Instituto Torcuato Di Tella.

Gurrieri, Paolo (1991): Technological and trade competition: a comparative analysis of the United States, Japan and the European Community, Roma, Universidad de Roma, mimeo.

Katz, Jorge y Bernardo Kosacoff (1989): El proceso de industrialización en la Argentina: evolución, retroceso y prospectiva, (LC/BUE/G. 104), Buenos Aires, Centro Editor de América Latina (CEAL).

Kosacoff, Bernardo, Jorge Todesca y Adolfo Vispo (1991): La transformación de la industria automotriz argentina. Su inte- gración con Brasil, Documento de Trabajo $\mathrm{N}^{\circ} 40$, (LC/BUE/ L. 122), Buenos Aires, CEPAL, Oficina en Buenos Aires.

Kosacoff, Bernardo (1992): El sector industrial argentino, Buenos Aires, CEPAL, mimeo.

Kosacoff, Bernardo y Daniel Azpiazú (1989): La industria argentina: desarrollo y cambios estructurales, (LC/BUE/G. 103), Buenos Aires, CEPAL/CEAL.

Lall, Sanjaya (1992): Technological capabilities and industrialization, World Development, vol. 20, N $^{\circ} 2,1992$, Nueva York Pergamon Press plc.

Mortimore, Michael (1992a): Un nuevo orden industrial internacional 1: La competencia internacional en un mundo que gira en torno a las empresas transnacionales, Santiago de Chile, CEPAL

(1992b): Un nuevo orden industrial internacional II: Incorporación o marginalidad para los países en desarrollo?, Santiago de Chile, CEPAL.

Mytelka, Lynn (1990): Crisis, Technological Change and Strategic Alliance.

OCDE (Organización de Cooperación y Desarrollo Económicos) (1991): Background Report Concluding the Technology Economy Program, París.

Oman, Charles (1984): New Forms of International Investment in Developing Countries, París, OCDE.

Ostry, Sylvia (1992): Governments \& Corporations in a Shrinking World: Trade and Innovation Policies in the United States, Europe and Japan, New York, Council on Foreign Relations Press.

Ozawa, Terutomo (1992): Foreign direct investment and economic development, en Transnational Corporations, vol. I, $\mathrm{N}^{\circ} \mathrm{I}$ Nueva York, Naciones Unidas.

Sourrouille, Juan, Francisco Gatto y Bernardo Kosacoff (1984): Inversiones extranjeras en América Latina. Politica económica, decisiones de inversión y comportamiento de las filiales, Buenos Aires, Instituto para la Integración de América Latina (INTAL)/Banco Interamericano de Desarrollo (BID).

Sourrouille, Juan, Bernardo Kosacoff y Jorge Lucángeli (1985): Transnacionalización y política económica en la Argentina, Buenos Aires, Centro de Economía Transnacional (CET)/CEAL.

Vernon, Raymond (1992): The role of transnationals in a hemisphere free trade area, Washington D.C., BID/CEPAL, mimeo.

Vispo, Adolfo y Bernardo Kosacoff (1991): Difusión de tecnologias de punta en la Argentina: algunas reflexiones sobre la organización industrial de I.B.M., Documento de trabajo, $\mathrm{N}^{\circ} 38$ (LC/BUE/L. 120), Buenos Aires, Oficina de la CEPAL en Buenos Aires. 